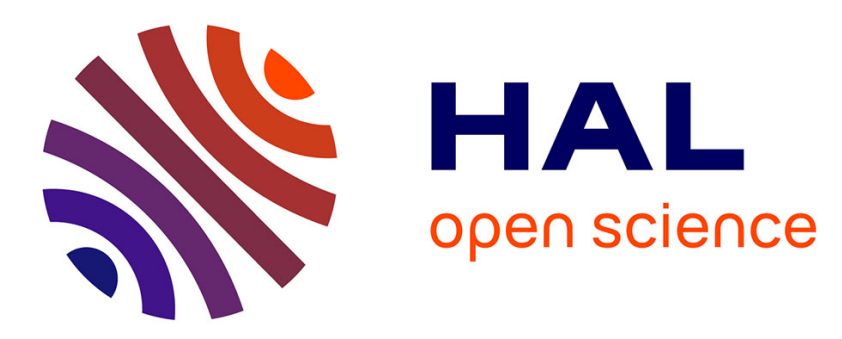

\title{
Impact of climate change on the northwestern Mediterranean Sea pelagic planktonic ecosystem and associated carbon cycle
}

\author{
Marine Herrmann, Claude Estournel, Fanny Adloff, Frederic Diaz
}

\section{To cite this version:}

Marine Herrmann, Claude Estournel, Fanny Adloff, Frederic Diaz. Impact of climate change on the northwestern Mediterranean Sea pelagic planktonic ecosystem and associated carbon cycle. Journal of Geophysical Research. Oceans, 2014, 119, pp.10.1002/2014JC010016. 10.1002/2014JC010016 . hal-01068504

\section{HAL Id: hal-01068504 https://hal.science/hal-01068504}

Submitted on 4 Jan 2022

HAL is a multi-disciplinary open access archive for the deposit and dissemination of scientific research documents, whether they are published or not. The documents may come from teaching and research institutions in France or abroad, or from public or private research centers.
L'archive ouverte pluridisciplinaire $\mathbf{H A L}$, est destinée au dépôt et à la diffusion de documents scientifiques de niveau recherche, publiés ou non, émanant des établissements d'enseignement et de recherche français ou étrangers, des laboratoires publics ou privés.

$$
\text { Copyright }
$$




\section{Journal of Geophysical Research: Oceans}

\section{RESEARCH ARTICLE \\ 10.1002/2014JC010016 \\ Impact of climate change on the northwestern Mediterranean Sea pelagic planktonic ecosystem and associated carbon cycle}

Key Points:

- Coupled physical-biogeochemical

simulations under present and future

climate

- Impact of climate change on NWMS

ecosystem evolution and carbon

cycle

- Estimation of uncertainties

associated with the modeling

configuration

Correspondence to:

M. Herrmann,

marine.herrmann@ird.fr

Citation:

Herrmann, M., C. Estournel, F. Adloff, and F. Diaz (2014), Impact of climate change on the northwestern

Mediterranean Sea pelagic planktonic ecosystem and associated carbon cycle, J. Geophys. Res. Oceans, 119, 5815-5836, doi:10.1002/

2014JC010016.

Received 4 APR 2014

Accepted 15 JUL 2014

Accepted article online 21 JUL 2014

Published online 8 SEP 2014

\author{
Marine Herrmann ${ }^{1}$, Claude Estournel2 ${ }^{2}$ Fanny Adloff33, and Frédéric Diaz4,5 \\ ${ }^{1}$ LEGOS, UMR 5566, CNRS - CNES - IRD - Université de Toulouse, Toulouse, France, ${ }^{2}$ LA, UMR 5560, CNRS - OMP - \\ Université de Toulouse, Toulouse, France, ${ }^{3}$ CNRM-GAME, UMR 3589, Météo-France - CNRS, Toulouse, France, ${ }^{4}$ Aix- \\ Marseille Université, CNRS/INSU, IRD, Mediterranean Institute of Oceanography, UM 110, Marseille, France, ${ }^{5}$ Université de \\ Toulon, CNRS/INSU, IRD, Mediterranean Institute of Oceanography, UM 110, La Garde, France
} lar by deep convection that could significantly weaken under the influence of climate change. Here we investigate the response of this ecosystem and associated carbon cycle to the long-term evolution of oceanic and atmospheric circulations. For that we developed a tridimensional coupled physicalbiogeochemical model and performed two groups of annual simulations under the climate conditions of respectively the 20th and the end of 21 st centuries. Our results suggest that the evolution of oceanic and atmospheric circulations does not modify the NWMS pelagic planktonic ecosystem and associated carbon cycle at a first order. However, differences mainly induced by the deep convection weakening and the surface warming are obtained at a second order. The spring bloom occurs 1 month earlier. Resulting from the decrease in nutrients availability, the bottom up control of phytoplankton development and bacteria growth by the nitrogen and phosphorus availability strengthens and the microbial loop intensifies as the small-sized plankton biomass increases. Carbon net fixation and deep export do not change significantly. The choice of the biogeochemical initial and boundary conditions does not change the representation
Abstract The northwestern Mediterranean Sea (NWMS) is biologically one of the most productive Mediterranean regions. NWMS pelagic planktonic ecosystem is strongly influenced by hydrodynamics, in particuof the ecosystem seasonal cycle, but the associated uncertainty range can be one order of magnitude larger than the predicted interannual and long-term variabilities. The uncertainty range of long-term trends associated with the physical forcing (hydrological, atmospheric, hydrodynamical, and socioeconomic) is much smaller $(<10 \%)$.

\section{Introduction}

According to IPCC [2013], the reality of climate change is now unequivocally established and is most likely due to anthropogenic greenhouse gases. The Mediterranean Sea could be particularly vulnerable to climate variations [Turley, 1999] and was identified as a hot spot for climate change [Giorgi, 2006]. It is indeed characterized by very short ventilation and water residence times compared to other oceanic zones [ $\sim 70$ years, MerMEx Group: Durrieu de Madron et al., 2011]. This specificity makes it a marine area where climate variations may strongly and rapidly impact hydrodynamics and marine ecosystems.

Effects of climate change were already observed on the Mediterranean hydrology. Hydrological observations showed that the temperature and salinity of the western Mediterranean deep water masses have increased by $0.0034^{\circ} \mathrm{C} \mathrm{yr}^{-1}$ and $0.0011 \mathrm{yr}^{-1}$ between 1959 and 1997 [Béthoux et al., 1998]. Numerical studies confirmed that climate change could induce a warming and a saltening of Mediterranean water masses, as well as an intensification of the water column stratification and a weakening of the thermohaline circulation and winter deep convection [Thorpe and Bigg, 2000; Bozec, 2006; Somot et al., 2006; Herrmann et al., 2008a]. Such changes of the physical characteristics of the Mediterranean Sea would impact the ecosystems functioning and the carbon oceanic sequestration in this region. In the northwestern Mediterranean Sea (NWMS) in particular, one of the most productive region of the Mediterranean Sea [Bosc et al., 2004], winter mixing associated with deep convection [Mertens and Schott, 1998] lifts allochtonous nutrients present in the deep layers up to the euphotic layer, inducing spring blooms. Summer primary production is rather associated with nutrients regenerated inside the surface layer through microbial loop activity. One could thus expect that the convection weakening might limits the penetration of carbon into the deep oceanic 
layers [as observed by Maier-Reimer et al., 1996; Sarmiento et al., 1998; Joos et al., 1999, in the global ocean], reduce the fertilizing role of the deep ocean and favor the dominance of small-size phytoplanktonic species adapted to higher temperatures and lower nutrients concentrations. Such an evolution of the planktonic communities structure could modify the ecosystem capacity to trap inorganic carbon.

Several studies attempted to examine the short to long-term variability of NWMS ecosystems using in situ data sets. Marty et al. [2002] observed a global increase in the total phytoplankton biomass between 1991 and 1999 at the DYFAMED station mainly associated with small-size phytoplankton and resulting from a lengthening of the stratification period. However, Marty and Chiaverini [2010] then analyzed a data set updated from 1995 to 2007 at the same site and obtained different results: they also observed an increase in total phytoplankton biomass but it was slower and mainly associated with large-sized phytoplankton. Analysis of multidecadal series in the NMWS [Kouwenberg, 1998; Molinero et al., 2005, 2008] also revealed significant changes in the zooplankton community structure and total abundance. Studies based on extended data set analysis suggested that those variations could be associated with a quasidecadal cycle rather than to a long-term change [Garcia-Comas et al., 2011]. Because of the scarcity of long-term data sets, it is therefore difficult to identify clear frequencies of fluctuation and trends in the functioning of NWMS ecosystems.

In this context, tridimensional coupled physical-biogeochemical modeling appears as a relevant approach to complement these long-term observations in order to understand and disentangle the effects of the interannual variability and long-term changes of atmospheric and oceanic conditions on the NWMS pelagic planktonic ecosystem. Modeling is indeed particularly suitable in the Mediterranean Sea where physical forcings show a strong spatiotemporal variability, and it enables to explore future climate periods that are by definition not accessible to observations. While numerous at the global scale [Bopp et al., 2005; Schmittner et al., 2008; Steinacher et al., 2010], very few 3-D modeling studies dealing with the effects of climate change on plankton community and productivity have been performed for the Mediterranean Sea. Lazzari et al. [2013] produced one projection of the Mediterranean biogeochemical functioning that suggested a stagnation of net carbon fixation between the 20th and 21st centuries. Chust et al. [2014] explored ecosystem responses to climate change with a focus on trophic amplification in European Seas, including Adriatic and Aegean Seas, two other Mediterranean areas where deep water formation occurs. Their results showed a large variability of responses depending on the regions that calls for further numerical studies. Except for these studies, biogeochemical modeling has mainly been used in this region to understand the effects of physical processes variability on the plankton ecosystem at higher frequencies [Lévy et al., 2001; Lazzari et al., 2011; Herrmann et al., 2013].

The objectives of the present study are to assess and understand the response of NWMS pelagic planktonic ecosystems to the long-term evolution of atmospheric and oceanic circulations (i.e., by the end of the 21 st century). For that, we adopt the same numerical approach as the one used by Herrmann et al. [2013] to examine the interannual variability of this ecosystem, based on the coupling between an eddy-resolving ocean circulation model and a multinutrients and multiplankton functional-type model. The numerical tools and simulations are described in section 2. The response of the main biogeochemical variables and processes to the long-term evolution of atmospheric and oceanic circulations by the end of the 21 st century is examined in section 3. Uncertainties in our projections are examined in section 4. Results are discussed and conclusions are presented in section 5 .

\section{Tools}

\subsection{The Coupled Model}

The coupled model is described in Herrmann et al. [2013]. The 3-D primitive equation ocean model SYMPHONIE [Marsaleix et al., 2009] is used to compute the circulation and the evolution due to the hydrodynamics of the planktonic pelagic ecosystem. This eddy-resolving model (3 km resolution) was used to study the NWMS circulation, in particular deep water formation over the shelf [Herrmann et al., 2008a] and in the open ocean [Herrmann et al., 2008b; Herrmann and Somot, 2008]. It is forced at the surface by heat, water, and momentum fluxes. Lateral oceanic forcing (temperature, salinity, horizontal velocity, and sea surface elevation) is applied at the open boundaries following Auclair et al. [2006]. The Rhone river freshwater discharge is introduced as a lateral boundary condition. The modeled area is shown in Figure 1. 


\section{QAGU Journal of Geophysical Research: Oceans}
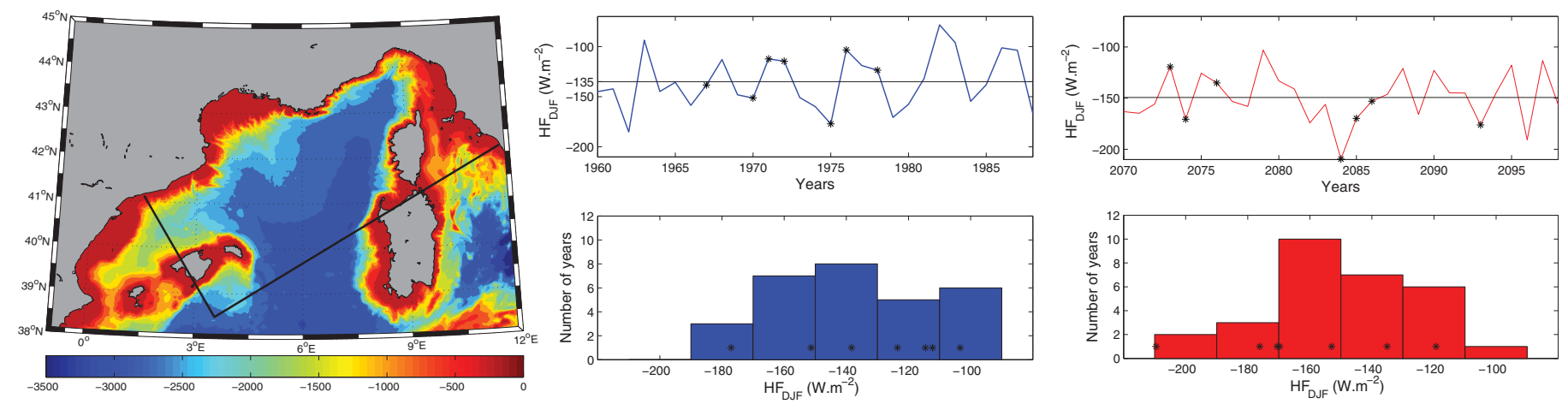

Figure 1. (left) NWMS bathymetry $(\mathrm{m})$ and (right) years selection from the December-February heat flux over the NWMS $H F_{D J F}$. (left) The black line indicates the boundary of the model domain. (right) Yearly time series of $H F_{D J F}$ during the present (blue) and future (red) period (top) and distribution of $H F_{D J F}$ (bottom). The selected years are indicated by stars.

The biogeochemical model is a multinutrient and multiplankton functional-type model that simulates the dynamics of several biogeochemical decoupled cycles of biogenic elements (carbon, nitrogen, phosphorus, and silicon) and of nonredfieldian pelagic plankton groups. Equations are detailed in Auger et al. [2011]. There are 6 main compartments (zooplankton, phytoplankton, heterotroph bacteria, particulate organic matter (POM, small (S) and large (L)), dissolved organic matter (DOM), and nutrients) and 33 state variables. The values of the model parameters are provided in Herrmann [2007]. The hydrodynamic model computes the evolution of each state variable associated with physical processes at each grid point and at each physical time step, and the biogeochemical model computes its biogeochemical evolution at each biogeochemical time step. The physical time steps are those of Herrmann et al. [2008a], of the order of a few seconds, and the biogeochemical time step is equal to $1 \mathrm{~h}$.

This coupled model was used by Herrmann et al. [2013] to study the influence of the interannual variability of atmospheric and oceanic conditions on the NWMS pelagic planktonic ecosystem. Comparisons with available in situ and satellite data showed that the model reproduces realistically the spatial and temporal evolution of this ecosystem and the associated biogenic elements cycles. Results suggested that the atmospheric and oceanic variability induces statistically significant differences in the whole ecosystem, in particular in the inorganic and organic carbon storage. We use the same approach to study the impact of climate change on the NWMS ecosystem.

\subsection{The Simulations}

\subsubsection{Hydrodynamics}

The hydrodynamical settings of the simulations were described by Herrmann et al. [2008a] who studied the impact of climate change on NWMS shelf dense water formation. Monthly averaged results of an oceanic simulation performed for the 1960-2099 period over the whole Mediterranean Sea by Somot et al. [2006] using the OPAMED8 eddy-permitting model were used to prescribe the initial and lateral boundary hydrodynamical conditions to SYMPHONIE. To force OPAMED8 and SYMPHONIE at the surface, daily air-sea fluxes were provided by a run performed with the atmospheric regional climate model ARPEGE-Climate for the 1960-2099 period [Somot et al., 2006]. This atmospheric free simulation (there is no assimilation) is divided into two periods. During the first 40 years, the greenhouse gases and aerosols concentrations correspond to the concentrations observed between 1960 and 1999. During the following 100 years, these concentrations increase following the IPCC A2 scenario. We use the same Rhone discharge as Somot et al. [2006], based on the climatological monthly UNESCO RivDis database [Vörösmarty et al., 1996] and taking into account its long-term evolution.

Since it was not technically possible to perform a multidecadal coupled simulation at a $3 \mathrm{~km}$ resolution, we selected two groups of seven representative years of the present climate period [defined as the 1961-1990 period of the ARPEGE-Climate simulation following the PRUDENCE project, Christensen et al., 2002] and of the future climate period (2070-2099). Deep convection strongly influences the dynamics of the NWMS pelagic planktonic ecosystem and highly depends on winter atmospheric buoyancy loss [Herrmann et al., 2010]. 
We therefore selected representative years by examining the average of this buoyancy loss over the NWMS during the coldest period, i.e., December-February, $H F_{D J F}$, and over the model domain for the present period of the ARPEGE-Climate simulation (Figure 1). For each period, we selected seven representative years with winter heat flux distributed over the whole range of the heat flux values (Figure 1). We then performed 14 corresponding simulations of the NWMS circulation using SYMPHONIE. Those hydrodynamic simulations are analyzed in details in Herrmann et al. [2008a]. Outputs are used to force the biogeochemical model in order to compute the tridimensional evolution of the pelagic planktonic ecosystem over the NWMS during those 14 years.

\subsubsection{Biogeochemical Initial Conditions}

When performing our simulations, no data were available to perform a tridimensional initialization of the biogeochemical variables. We therefore used the method explained in Herrmann et al. [2013]: we used vertical profiles obtained at DYFAMED in January 2004 to initialize the biogeochemical variables over the whole domain. We then performed for both periods (present and future) a biogeochemical simulation beginning in January and forced several years in loop by the results of the hydrodynamical simulation of the most average year (in terms of $H F_{D J F}$, see Figure 1) of the 7 year group. In September of the third year both simulations are stabilized. We then performed for each year a biogeochemical run initialized by the tridimensional outputs of those simulations, forced by the results of the corresponding hydrodynamical simulation and running from September to next September. At the end, we obtained two groups of seven annual biogeochemical simulations who can be considered as the twins of the hydrodynamical simulations analyzed in Herrmann et al. [2008a].

\subsubsection{Biogeochemical Boundary Conditions}

For the same reasons as above, no information concerning the lateral boundaries fluxes was available. To overcome this problem, we applied a buffer zone of 20 points width along the lateral open boundaries, where the model only runs along the vertical dimension. For incoming fluxes, the value of the state variable at the first point of the domain where the model runs tridimensionally is given by the average of the points of the buffer zone. For the outgoing fluxes, the concentration is computed "classically" using the values of the inner domain.

Data available to assess the highly episodical fluxes of organic and inorganic matter of atmospheric origin are extremely scarce, we therefore neglected them. Nutriments and organic matter fluxes at the sea bottom due to diagenesis or sediment resuspension were also neglected.

For organic and inorganic matter coming from the Rhone river, we applied the monthly in situ concentration data provided by the "Rhone-Mediterranee" monitoring network for 2003-2004. Annual mean values are given in Herrmann et al. [2013]. No projection of matter discharges by the end of the 21 st century were available. We therefore used those values for both the present and future periods. Note however that the long-term evolution of the river water discharge is taken into account following Somot et al. [2006], the quantitative change of matter discharge associated with this evolution is therefore represented.

\section{Impact of Climate Change}

In this section, we investigate the impact of climate change on the NWMS pelagic planktonic ecosystem in considering the area of study as a whole. For that, we compare the seven annual simulations performed for the future period with the seven simulations performed for the present period, analyzed in Herrmann et al. [2013]. We performed budget analysis, computing the spatial averages over the model domain of the main variables and processes, and their annual averages. To determine quantitatively if the present and future groups of simulations are significantly different from each other, we performed statistical hypothesis Student's $t$ test between both groups. $t$ test is performed for each value of the variables and processes studied hereafter, and the corresponding evolution of the $p$ value is plotted above their graphs (e.g., Figure 2). A p value smaller than 0.05 indicates that present and future groups are significantly different. For the hydrodynamic and biogeochemical variables and processes examined here, we indicate in the first two columns of Tables 1 and 2 the values of the average and the standard deviation over the 7 years of the present period, of the average over the 7 years of the future period and the variation compared to the present period and of the $\mathrm{p}$ values between both periods $p$. 


\section{QAGU Journal of Geophysical Research: Oceans}
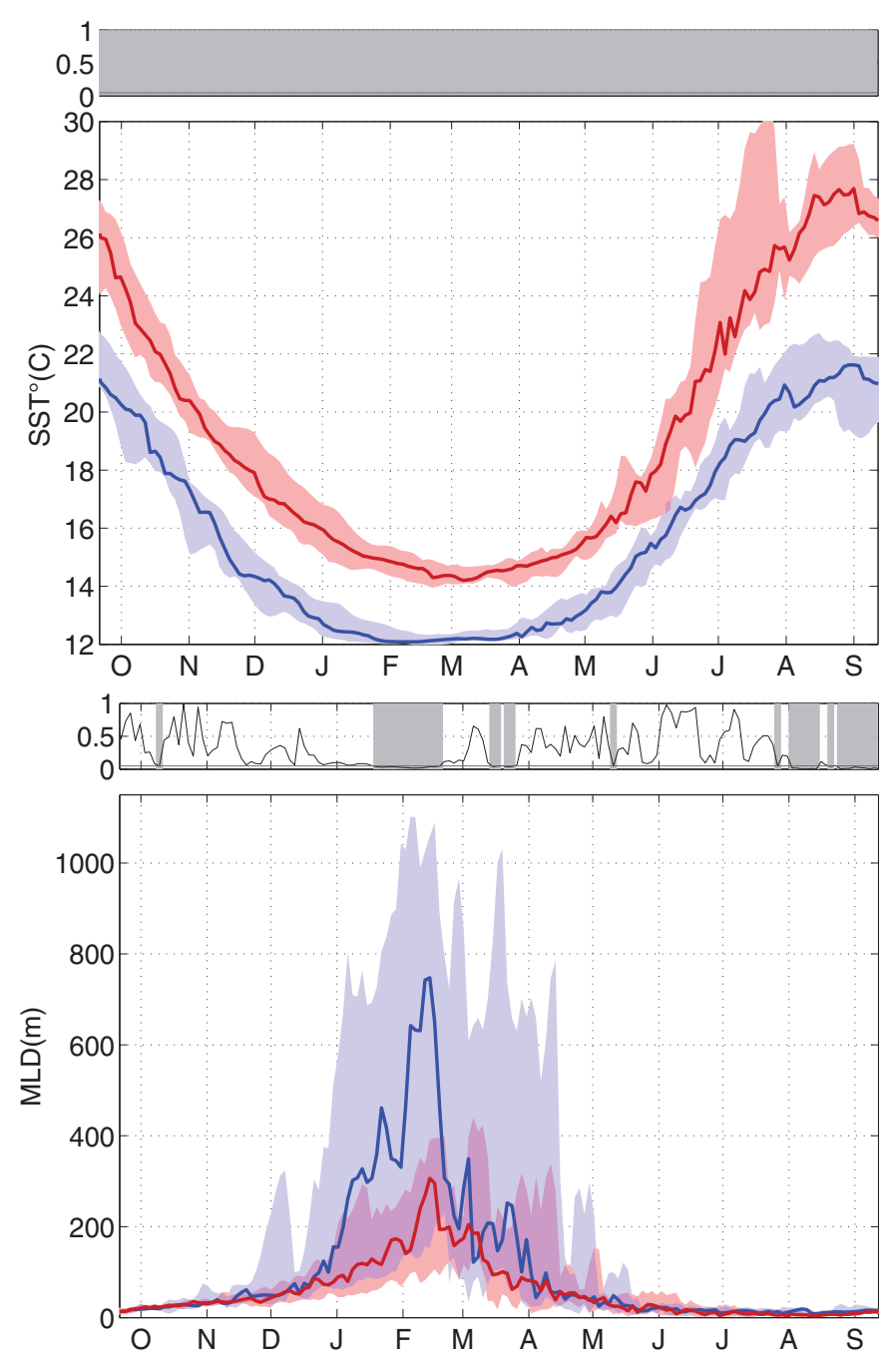

Figure 2. Time series of the mixed layer depth and of the mean surface temperature averaged over the whole domain, MLD and SST, for the present (blue) and future (red) periods. For both periods we show the median (thick lines) and the envelope of the 7 years (shaded areas). The black line above each graph shows the evolution of the associated $p$ value, with periods of $p$ value $<0.05$ highlighted in gray.

\subsection{Hydrodynamic Characteristics}

Somot et al. [2006] and Herrmann et al. [2008a] investigated the impact of climate change on the NWMS oceanic circulation. They showed that in the hydrodynamics simulations used here, climate change induces a strong weakening of shelf and open ocean convection, an intensification of the water column stratification and a warming of the water masses by the end of the 21st century. This evolution is visible in Figure 2 that shows the annual cycle of the mixed layer depth [MLD, defined using a vertical diffusion coefficient threshold value of $4 \mathrm{~cm}^{2} \mathrm{~s}^{-1}$ [Herrmann et al., 2008b] and sea surface temperature (SST) averaged over the NWMS. The SST is warmer for the 7 years of the future period than for the years of the present period and the difference between both periods is statistically significant during the whole year. The average annual warming $\left(3.4^{\circ} \mathrm{C}\right)$ is 10 times larger than the interannual variability in the present period (Table 1). The winter deepening of the mixed layer associated with convection strongly weakens: the annual maximum MLD does not exceed $400 \mathrm{~m}$ in the future period, versus $1100 \mathrm{~m}$ in the present period. At a daily timescale, the

difference of MLD between both periods is not always statistically significant because of its strong high-frequency variability. However, at the annual scale, the $52 \%$ decrease is statistically significant (Table 1).

\subsection{Impact of Climate Change on the NWMS Pelagic Planktonic Ecosystem}

In this section, we examine the response of the different components of the NWMS pelagic planktonic ecosystem to the long-term evolution of oceanic and atmospheric conditions. The seasonal evolution of the biogeochemical variables obtained for the present and future periods is showed in Figure 3 . The $200 \mathrm{~m}$ layer was chosen to compute average values for the different ecosystem components because it contains most of the planktonic components and includes the euphotic layer [Herrmann et al., 2013]. At a first order, the seasonal evolution of the concentration of each ecosystem component is similar for both periods. In terms of seasonal and interannual variability, the functioning of the NWMS pelagic planktonic ecosystem is therefore not fundamentally different between the present and future periods. However, quantitative differences can be observed at a second order. In the following of this section, we describe and comment those differences. 


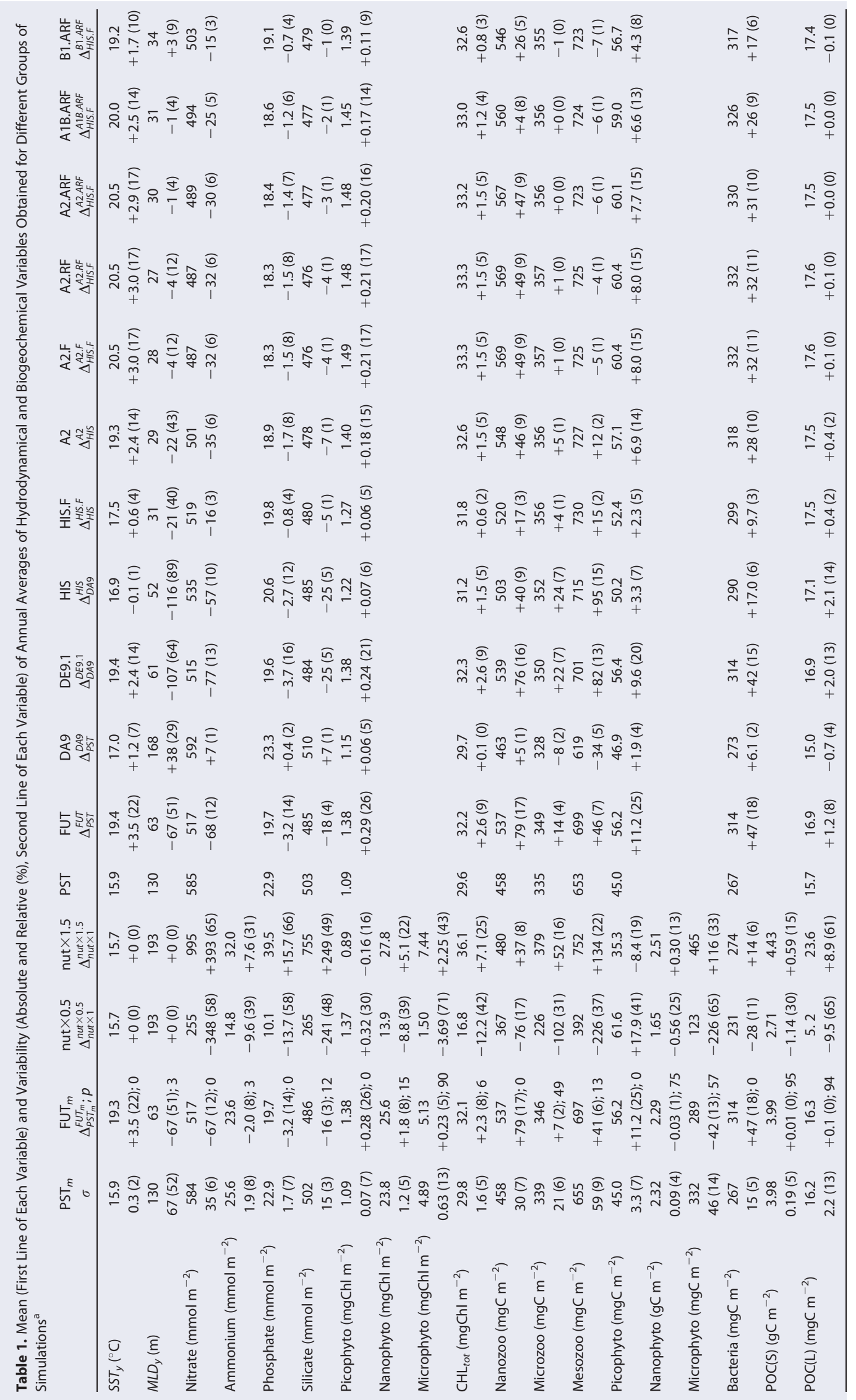




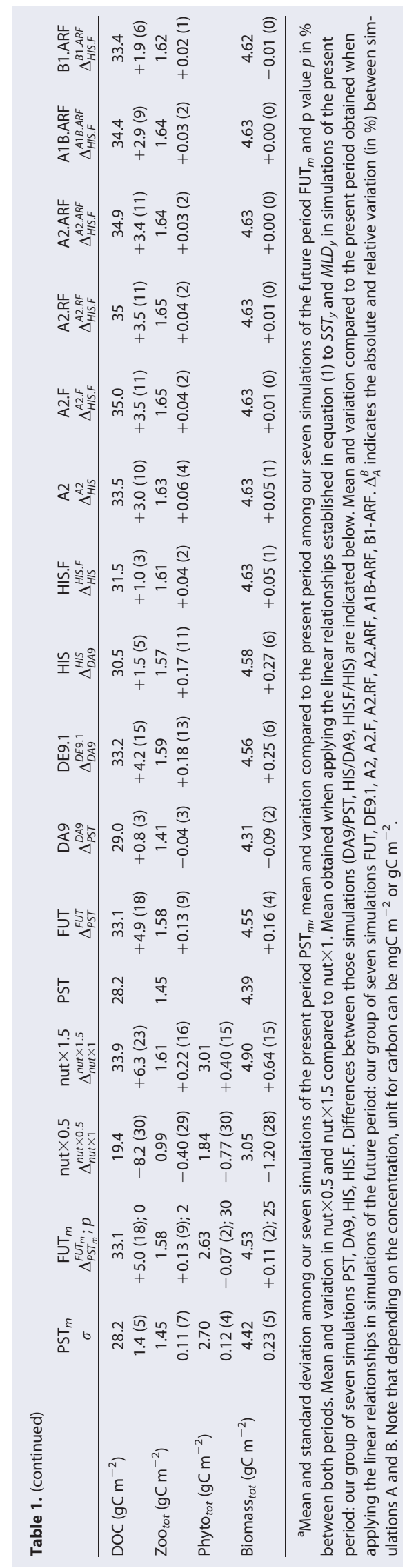




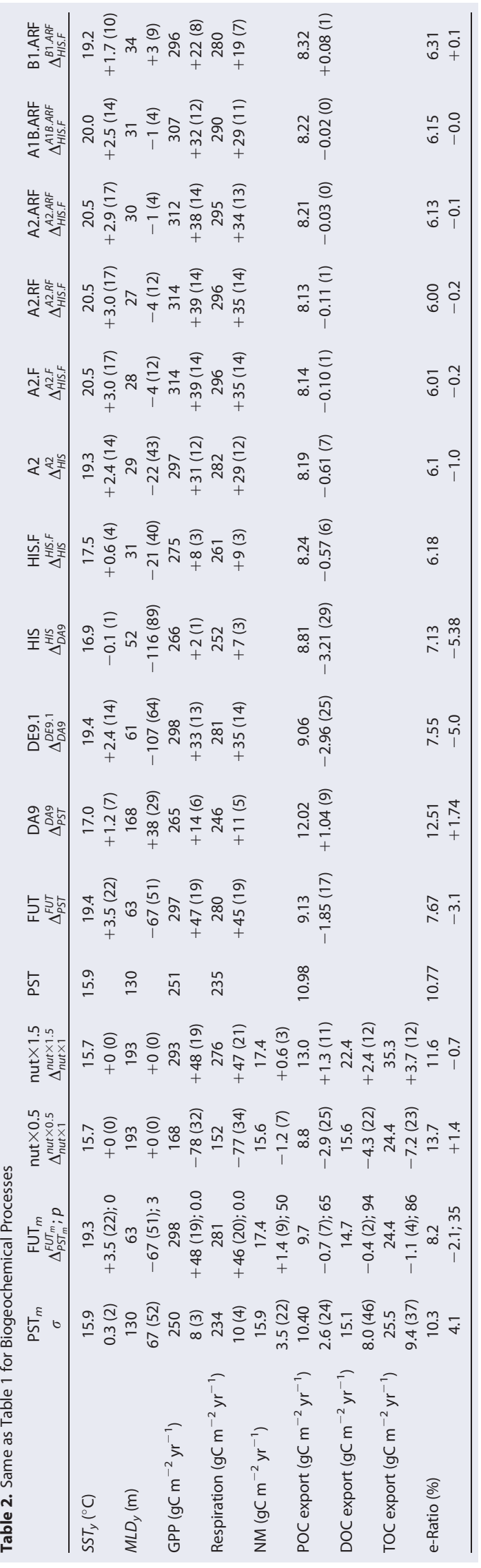




\section{QAGU Journal of Geophysical Research: Oceans}
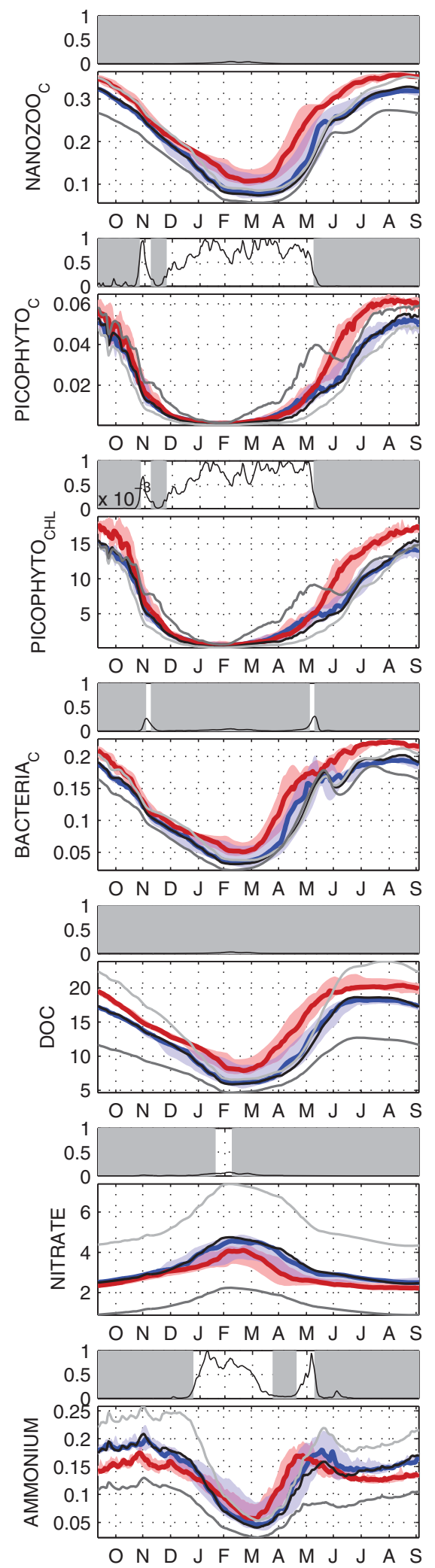
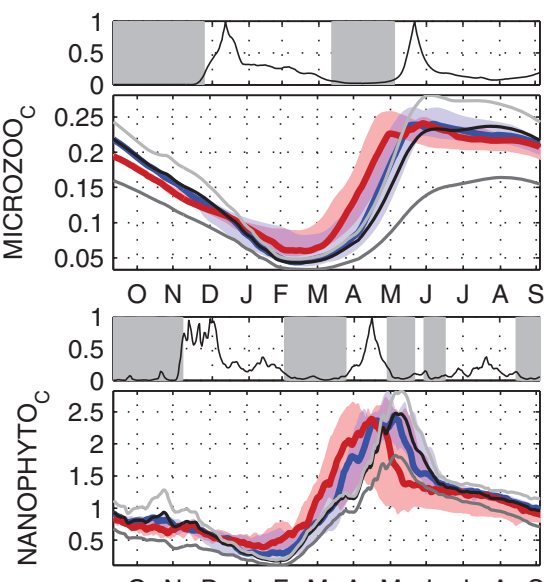

O N D J F M A M J J A S
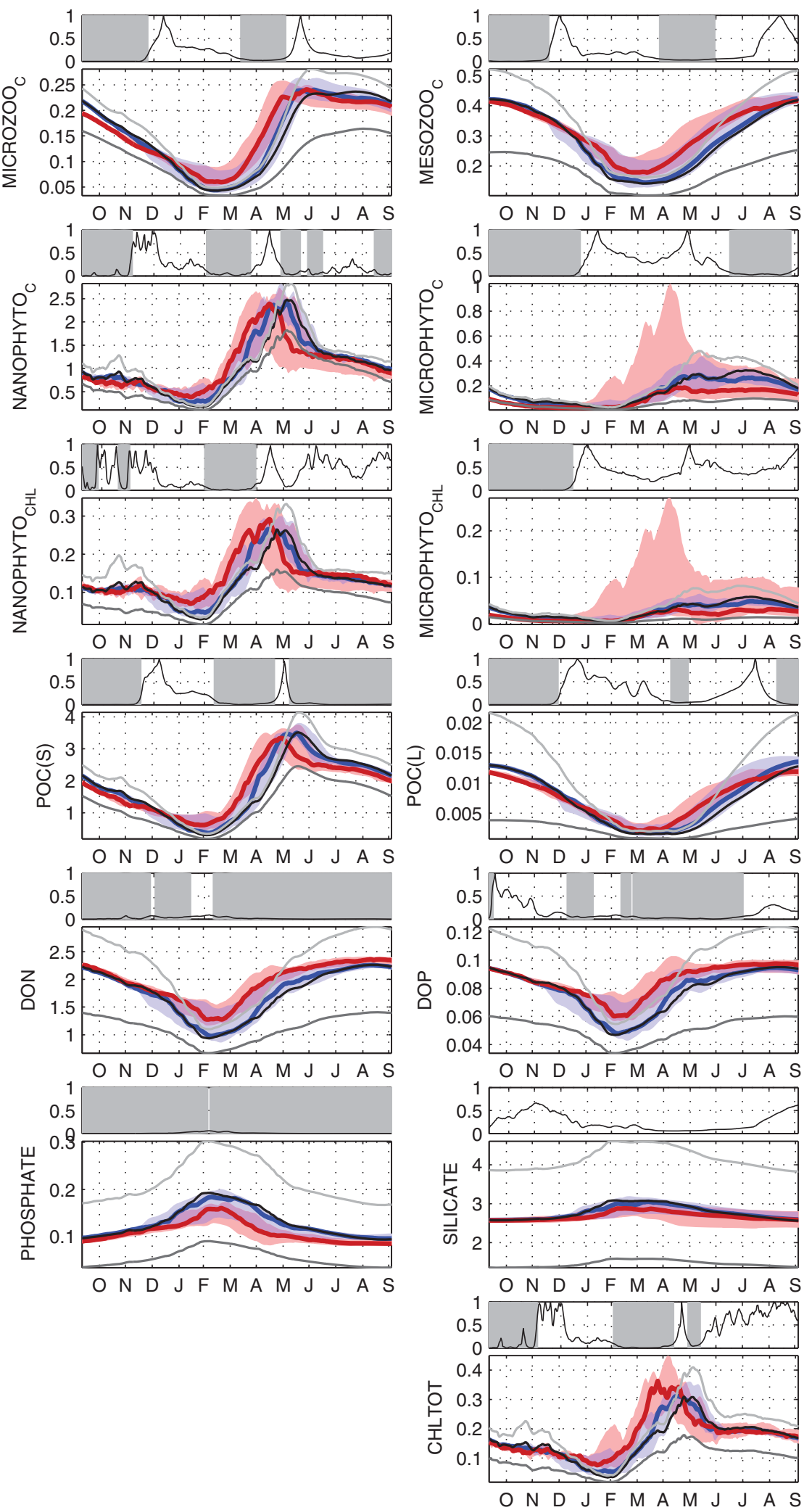

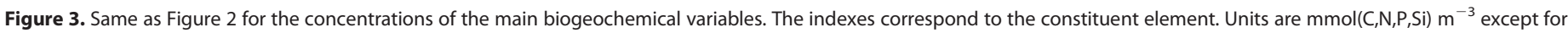
chlorophyll $\left(\mathrm{mgChl} \mathrm{m}^{-3}\right)$. The dark gray, black, and light gray curves correspond respectively to the results obtained for nut $\times 0.5$, nut $\times 1$, and nut $\times 1.5$. 


\subsubsection{Nutrients Availability}

Due to the weakening of the winter mixing between the present and future periods, the surface layer enrichment in allochtonous nitrate and phosphate decreases (Figure 3, Table 1). Following Herrmann et al. [2013], the nitrate concentration in the upper $200 \mathrm{~m}$ layer constitutes our indicator of the nutrients availability. Our results show a statistically significant average $12 \%$ decrease of the annual mean of this indicator between the present and future periods (Table 1). This negative trend is consistent with predictions obtained for low and midlatitudes by coupled carbon cycle-climate earth models [Marinov et al., 2010; Steinacher et al., 2010]. During the stratified period (June-November), the ammonium, nitrate and phosphate concentrations are lower in the future period than in the present period (by resp. $\sim 20 \%, 10 \%$, and $10 \%$ for the median curves, Figure 3), and those differences are significant. This could be due to an increase in their consumption during this period (in particular for ammonium, which is produced in the euphotic layer) and/ or to a limitation of the nitrate and phosphate upward fluxes due to the stratification increase.

The evolution of the average nitrate:phosphate in the surface layer is showed in Figure 4. It increases between the present and future periods, and this increase is significant most of the year. This suggests an intensification of the control of phytoplankton development and bacteria growth by the phosphorus availability.

The case of silicate (consumed by microphytoplankton only) is different. Its concentration does not significantly vary between both periods (Figure 3, Table 1). This suggests that the decrease in the microphytoplankton concentration (Figure 3), hence in the silicate consumption, counterbalances the decrease in the upward diffusive flux of silicate. The nitrate:silicate ratio decreases significantly between both periods during the whole year (Figure 4), suggesting a potential weakening of the control of microphytoplankton development by silicon availability consistent with the observed concentrations trends.

Note that our model does not take into account the long-term evolution of the nutrients concentration associated with the human activity, due to the lack of available estimation. For example, Béthoux et al. [2002] observed a long-term increase in the nitrate and phosphate concentrations in the NWMS, which could be partly explained by the increase in terrestrial and atmospheric inputs of anthropogenic origin.

\subsubsection{Phytoplankton}

The annual total chlorophyll biomass increases in average by $8 \%$ between the present and future periods (Table 1). This increase is mainly associated with the winter mixing and spring bloom periods (FebruaryMay), whereas the total chlorophyll biomass does not change statistically significantly during the stratified summer-fall period (Figure 3). It can be attributed to the convection weakening and surface warming (Figure 2), which favors the photosynthesis in our model since the temperature influence on primary production is parameterized through an exponential Eppley [1972]-type term [equations (A.17) and (A.57) of Auger et al., 2011]. The spring bloom occurs between mid-March and end of April for the future period, i.e., 1-1.5 month earlier than for the present period (mid-April to mid-May). Comparing their surface chlorophyll data with those of Morel and André [1991], Bosc et al. [2004] observed a 1 month lag of the spring bloom occurrence over a 20 year period. They attributed it to the convection weakening and to the euphotic layer warming during this period. Our modeling study therefore leads to conclusions that are consistent with those observational studies.

The total phytoplankton carbon biomass does not change significantly between the present and future periods (Table 1), similar to the one obtained by Chust et al. [2014] for the Adriactic Sea but opposite to the one obtained for the Aegean Sea. Its contribution to the total carbon biomass significantly decreases by $3 \%$ between the present and future periods $(p=0.2 \%)$, though it remains predominant ( $58 \%$ in average). Resulting from the combined increase of chlorophyll biomass and stagnation of carbon biomass, the $\mathrm{C}: \mathrm{Chl}$ ratio (not shown) decreases from $86 \mathrm{gC} \mathrm{gChl}^{-1}$ to $79 \mathrm{gC} \mathrm{gChl}^{-1}(p=2.5 \%)$. This evolution is related to the phytoplankton adaptive processes. First, because of the surface layer depletion, phytoplankton develops deeper, where the light availability is weaker, inducing a decrease in the $\mathrm{C}: \mathrm{Chl}$ ratio by photoadaptation [Cullen, 1990]. Second, as we will see later, the nutrient depletion induces a $34 \%$ increase in the average DOC exudation, $\sim 2$ times larger than the 19\% increase in the annual GPP. This results in smaller C:Chl ratio for every phytoplankton groups.

The microphytoplankton and nanophytoplankton chlorophyll and carbon biomasses, as well as their relative contribution to the total phytoplankton biomasses, do not show statistically significant variations 

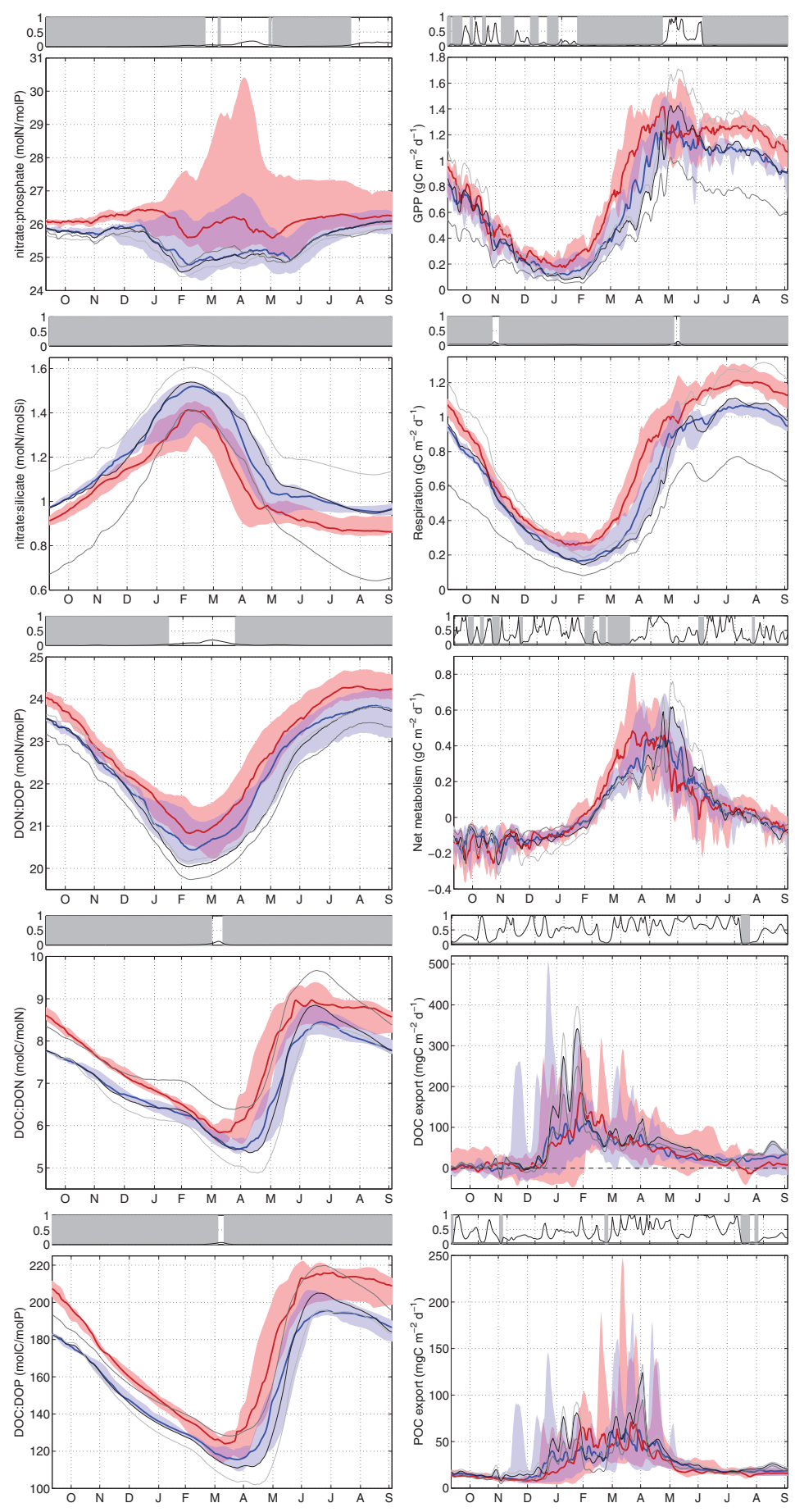

Figure 4. (left) Same as Figure 3 for the ratios between the concentrations of dissolved organic and inorganic nitrogen, phosphorus, silica, and carbon and (right) for the biogeochemical processes governing the carbon cycle.

between the present and future periods (Table 1). However, the microphytoplankton interannual variability is very pronounced in the future period (92\%), with two particular years during which the spring microphytoplankton bloom is very strong. In the present paper, we chose to focus on climate change on a statistical point of view. The detailed analysis of the specificities of each year is therefore beyond our scope; moreover, it would be necessary to perform a larger number of annual simulations in order to explain statistically those specificities. Note however that it seems that an early end of winter convection and a weak availability of phosphate relative to silicate could induce a competition between micro and nanophytoplankton that 
sometimes would result in stronger microphytoplankton development. Picophytoplankton chlorophyll and carbon biomasses show statistically significant average increases $(\sim+25 \%$, Table 1$)$, mainly associated with the increase occurring during the summer-fall stratified period (Figure 3). Its contribution to the total phytoplankton biomass increases very slightly $(\sim+1 \%)$, but this change is statistically significant $(p=0.5 \%)$. This could be attributed partly to the euphotic layer warming, but also to the increase during the stratified period of bacteria excretion of ammonium (see section 3.2.4) that phytoplankton consumes preferentially [Herrmann, 2007]. This predicted evolution of phytoplankton community structure is in agreement with recent global modeling and field studies for midlatitudes [Bopp et al., 2005; Cermeno et al., 2008; Marinov et al., 2010; Moran et al., 2010].

\subsubsection{Organic Matter}

The spring increase in small and large POM occurs 1 month earlier in the future period, due to the earlier occurrence of the spring bloom (Figure 3). The interannual variability of its seasonal evolution remains weak. The average annual POM biomass does not change significantly between the present and future periods (Table 1).

Between the present and future periods, the average annual DOM concentrations increase $(+18 \%$ for DOC, $p=0 \%$, Table 1). During the winter mixing and spring bloom period, DOC, DON, and DOP concentrations are all larger in the future period, and $p<5 \%$ most of the time. During the stratified summer, the DOC concentration is $\sim 15 \%$ larger for the future than for the present period ( $p<5 \%$ ) while concentrations of DON, and especially of DOP (with $p>5 \%$ in July-August), progressively reach the same range for both periods (Figure 3). This can be explained as a combined effect of nutrient depletion and GPP increase (Table 2), which induces during the period of phytoplankton development a relative increase in the DOC phytoplanktonic exudation that is stronger than the increase in DON and DOP exudation. The DOC accumulation is also due to the activation by higher temperature of processes as natural phytoplankton mortality that produces POM and bacterial remineralization of POM into DOM. The formulation of those processes in our model indeed also take into account the influence of temperature through Eppley-type exponential terms similar as the one used for GPP [Herrmann, 2007]. In winter, phytoplankton development is low and the DOM concentrations increase during this period can be attributed to the weakening of convection hence of DOM vertical dilution rather than to an increase in the DOM phytoplanktonic exudation.

Following this evolution of DOM concentrations, the DOC:DON and DOC:DOP ratios increase during the whole year ( $p<5 \%$ most of the year) and this increase is $\sim 10 \%$ stronger during spring and summer (Figure 4). The DON:DOP ratio increases the whole year, in average by $\sim 0.5$ (Figure 4 ), with $p<5 \%$ most of the year. The evolution of those DOM concentrations and their ratios therefore suggests an enhancement of the control of both phytoplankton development and bacteria growth by nutrients availability, particularly phosphorus, between the present and future periods.

\subsubsection{Bacteria}

The spring development in bacteria biomass associated with the consumption of the DOM exuded by the phytoplankton during the spring bloom occurs earlier in the year in the future period (midMarch versus mi-April for the present period, Figure 3). The average bacteria carbon biomass show a statistically significant increase during the whole year between the present and future periods (18\% in average, Table 1) consequently to the increase in phytoplankton DOM exudation. Bacteria contribution to the total carbon biomass increases weakly by $1 \%$ but this change is statistically significant $(p=0.0 \%)$.

Bacteria preferentially consume DOM but can consume ammonium and phosphate in case of DON and DOP depletion [Auger et al., 2011]. As for the present period, in the future period bacteria never consume ammonium whereas they systematically consume phosphate (between April and October). This consumption increases by $163 \%$ between both periods, although it is still negligible compared to the DOP bacteria uptake $(<1 \%)$. The ratio between the bacteria excretion of ammonium, resp. phosphate, and the bacteria uptake of DON, resp. DOP, decreases slightly but significantly between both periods (77 to $75 \%$, resp. 49 to $44 \%$, between the present and the future periods; $p=0.0 \%$ ) but stays larger for nitrogen than for phosphorus. These results confirm the intensification by the end of the 21 st century of the control of the bacteria growth by nitrogen and phosphorus availability, with a stronger predominance of the phosphorus control. 


\subsubsection{Zooplankton}

In the future period, the total zooplankton carbon biomass increases during the whole year (Figure 3), in average by $9 \%$ (Table 1$)$. This statistically significant increase $(p=1.8 \%)$ is related both to the weakening of deep convection and to the increase in some preys availability (bacteria, small phytoplankton, and zooplankton groups). This evolution is of the same sign and order of magnitude as that computed by Chust et al. [2014] for the Adriatic Sea but opposed that for the Aegean Sea. The contribution of the zooplankton to the total carbon biomass increases statistically significantly $(p=1 \%$ ) by $2 \%$, from $33 \%$ to $35 \%$. Sixty-one percent of the zooplankton biomass increase is due to the nanozooplankton biomass that increases significantly by $17 \%$ (Table 1). This nanozooplankton biomass increase is related to the significant increases of its prey availability, bacteria, and picophytoplankton and associated with a significant increase of its predation rate (not shown).

Even if not significant at an annual basis, the increase of mesozooplankton biomass between both periods is significant during the spring bloom, when the availability of its preys (microphyto and zooplankton, small POM) is also significantly larger (Figure 3). This direct response of mesozooplankton to an increase in prey availability is partly artificial. These metazoans plankton have indeed complex life cycles composed of different larval stages and their lifetime are impacted by environmental variables [turbulence, temperature, etc., Eisenhauer et al., 2009]. This complexity is not taken into account in our model, which is more able to mimic the dynamics of unicellular organisms as protist grazers, represented here by micro and nanozooplankton. These unicellular organisms have more simplistic life cycles and are more able to directly respond to variations in potential preys and temperature. Yet $68 \%$ of the zooplankton increase is due to those protist grazers, especially nanozooplankton (61\%). Even if the (not statistically significant) trend obtained on mesozooplankton has to be considered with cautious, we can trust the statistically significant increase in nanozooplankton biomass.

\subsection{Impact of Climate Change on the Biogeochemical Processes}

In this section, we examine the long-term evolution between the 20th and the end of the 21st centuries of the functioning of the main biogeochemical processes of the pelagic planktonic ecosystem and the carbon balance in the NWMS.

\subsubsection{Gross Primary Production GPP}

Figure 4 shows the evolution of the average GPP over the model domain. As for the present period, this evolution shows a very weak interannual variability during the future period ( $3 \%$, Table 2 ). The GPP follows the same long-term evolution as the chlorophyll biomass (section 3.2.2), and its spring maximum occurs 1 month earlier in the future period. Though the nutrient availability decreases between the present and future periods, the GPP increases statistically significantly (in average by 19\%), in particular during the stratified period. This increase is induced by the water warming. In the GPP equation [equation (A17) of Auger et al., 2011], the Eppley [1972]-type parameterization of the temperature influence involves a term of the form $Q_{10}^{\frac{T-T_{1}}{T_{2}}}$ with $Q_{10}=2.01, T_{1}=20^{\circ} \mathrm{C}$ and $T_{2}=10^{\circ} \mathrm{C}$. Between the present and future periods, the surface temperature in the NWMS increases in average by $2.49^{\circ} \mathrm{C}$. Such an increase would theoretically induce a $Q_{10}^{\frac{2.49}{T_{2}}}-1$ $=19 \%$ increase in the GPP, which corresponds exactly to what we obtain. This predicted pattern for the GPP is opposite to some of the projections provided by global coupled models [Bopp et al., 2001; Frolicher et al., 2009; Steinacher et al., 2010]. Other studies however showed a GPP increase during the 21st century, for the global ocean [Sarmiento et al., 2004; Schmittner et al., 2008] and the whole Mediterranean Sea [Lazzari et al., 2013, +5\%].

\subsubsection{Respiration and Net Metabolism}

Figure 4 shows the evolution of the dissolved inorganic carbon production associated with the NWMS pelagic planktonic ecosystem respiration. As for the other processes, its seasonal evolution and interannual variability are very similar for both periods, with an earlier spring rise in the future. The dissolved inorganic carbon production is stronger in the future than in the present period, particularly in summer, and this increase is statistically significant the whole year. The annual value increases in average by $20 \%$ (Table 2). This is consistent with the results of Vasquez-Dominguez et al. [2007] who show that in a NWMS coastal area, a $2.5^{\circ} \mathrm{C}$ water warming induces a $23 \%$ increase in the respiration rate of the planktonic community. Bacteria respiration contributes to $87 \%$ of its increase. The GPP increase resulting from the water column 
warming and the respiration rate increase resulting from the bacteria activity intensification are therefore very similar ( $\left.\sim 50 \mathrm{gC} \mathrm{m}^{-2} \mathrm{yr}^{-1}\right)$. Lazzari et al. [2013] obtained a similar result at the Mediterranean scale. The net metabolism consequently does not change significantly between both periods (Figure 4, Table 2) and remains positive for all the years, suggesting that the NWMS would remain a sink area for inorganic carbon at the end of 21 st century regarding the activity of pelagic planktonic ecosystem.

\subsubsection{Organic Carbon Bottom Export}

The seasonal evolution of the organic matter deep export is similar for the present and future periods (Figure 4). The export mainly occurs between January and June, i.e., during the winter mixing and spring bloom. We showed in Herrmann et al. [2013] that it is mainly related to convection intensity. Between the present and future periods, this intensity strongly decreases ( $-52 \%$ for the annual average MLD, Table 1$)$. On the other side, the DOC concentration increases significantly $(+8 \%$, Table 1$)$ while the total particulate carbon (POC and heterotroph and autotroph phytoplankton) does not change significantly. As a result, the export of organic carbon does not change significantly between both periods (Table 2). Those results are in agreement with projections obtained over midlatitudes for the 21 st century from global coupled carbon-climate models [e.g., Joos et al., 1999; Bopp et al., 2001; Frolicher et al., 2009; Steinacher et al., 2010]. Finally, the ratio between the export production and the GPP (the e-ratio) does not undergo a statistically significant change and remains $\sim 10 \%$ (Table 2), suggesting that the contribution of regenerated production to the total GPP remains stable and largely predominant in the NWMS.

\section{Uncertainties}

Our simulations were performed using one biogeochemical model (Eco3M) forced by one hydrodynamical NWMS model (Symphonie), itself forced by forcing data sets obtained thanks to single Mediterranean-scale Atmospheric and Oceanic Regional Climate Models [ARCM and ORCM, respectively ARPEGE-Climate and OPAMED8, Somot et al., 2006] forced by one Atmosphere Ocean Global Climate Model (AOGCM, ARPEGEClimate and OPA), under one scenario hypothesis [A2, IPCC, 2001]. This strategy induces uncertainties associated with the choices made at each level of the modeling configuration. We address this question in this section, providing estimates of the uncertainties related to the choice of the scenario, of the physical forcing (atmospheric, river, open boundary) and of the biogeochemical forcing (initial and boundary conditions).

\subsection{Uncertainties Related to the Physical Forcing}

To test the sensitivity to the physical forcing, we adopted the strategy used by Herrmann et al. [2008a] when examining the impact of interannual variability and climate change on dense water shelf formation and cascading.

First, we identified which variables or processes are clearly influenced by the hydrodynamical conditions: these variables or processes would most likely be affected by the choice of the physical forcing. For that, we calculated the correlation coefficients $C_{S S T}$ and $C_{M L D}$ (and associated levels of significance $S L$ ) between the vector $V_{\text {bio }}$ of 14 annual values obtained in our 2 groups of 7 simulations for a given biogeochemical variable or process on one side, and the vectors $S S T_{y}$ and $M L D_{y}$ of 14 annual values obtained for variables representative of the physical conditions in this study, i.e., SST and MLD, on the other side. For each variable or process for which the relation with physical forcing is statistically significant, i.e., SL $>0.95$ for $C_{S S T}$ and/or $C_{M L D}$, we performed (bi)linear regressions of the form

$$
V_{b i o}=b+a_{S S T} \times S S T_{y}+a_{M L D} \times M L D_{y}
$$

We then computed the error

$$
\epsilon_{V_{\text {bio }}}=\frac{\sum_{n=1}^{14}\left|V_{b i o, L R}-V_{b i o, \bmod }\right|}{14 \times\left(\max \left(V_{b i o, \bmod }\right)-\min \left(V_{\text {bio,mod }}\right)\right)}
$$

where $V_{b i o, m o d}$ is the annual value given by the model and $V_{b i o, L R}=b+a_{S S T} \times S S T_{y}+a_{M L D} \times M L D_{y}$ is the value obtained when applying the (bi)linear regression equation to $S S T_{y}$ and/or $M L D_{y}$. Results are presented in Table 3. Eighteen out of the twenty-seven main biogeochemical variables or processes are statistically significantly correlated with SST and/or MLD: all allochtonous nutrients (nitrate, phosphate, and silicate); total 


\begin{tabular}{|c|c|c|c|c|c|c|c|}
\hline Process or Variable & $p(\%)$ & $C_{S S T}(\%)$ (and SL) & $C_{M L D}(\%)($ and $S L)$ & $a_{S S T}$ & $a_{M L D}$ & $b$ & $\epsilon V_{\text {bio }}(\%)$ \\
\hline SST & 0.0 & & $-68(0.992)$ & & & & \\
\hline MLD & 2.5 & $-68(0.992)$ & & & & & \\
\hline \multicolumn{8}{|c|}{ Biogeochemical processes } \\
\hline GPP & 0.0 & $95(1.00)$ & $-67(0.99)$ & 12.9 & $-2.49 \times 10^{-2}$ & 50.0 & 7.7 \\
\hline RESP & 0.0 & $95(1.00)$ & $-73(1.00)$ & 11.7 & $-6.82 \times 10^{-2}$ & 58.9 & 6.9 \\
\hline NM & 50 & $13(0.35)$ & $27(0.65)$ & & & & \\
\hline DOC exp & 94 & $-10(0.26)$ & $49(0.93)$ & & & & \\
\hline POC exp & 65 & $-22(0.55)$ & $60(0.98)$ & & $2.76 \times 10^{-2}$ & 7.38 & 21.2 \\
\hline TOC exp & 86 & $-13(0.35)$ & $53(0.95)$ & & & & \\
\hline e-ratio & 35 & $-35(0.77)$ & $68(0.99)$ & & $4.62 \times 10^{-2}$ & 4.74 & 16.8 \\
\hline \multicolumn{8}{|c|}{ Nutrients concentrations } \\
\hline Nitrate & 0.3 & $-80(1.00)$ & $88(1.00)$ & -10.0 & $4.94 \times 10^{-1}$ & $6.79 \times 10^{2}$ & 9.8 \\
\hline Phosphate & 0.3 & $-81(1.00)$ & $88(1.00)$ & $-4.71 \times 10^{-1}$ & $2.38 \times 10^{-2}$ & 27.3 & 9.8 \\
\hline Silicate & 12 & $-56(0.96)$ & $75(1.00)$ & $-9.25 \times 10^{-1}$ & $2.15 \times 10^{-1}$ & $4.89 \times 10^{2}$ & 14.7 \\
\hline Ammonium & 2.5 & $-50(0.93)$ & $-21(0.53)$ & & & & \\
\hline \multicolumn{8}{|c|}{ Chlorophyll concentrations } \\
\hline Phyto $_{\text {tot }}$ & 5.9 & $62(0.98)$ & $-60(0.98)$ & $4.97 \times 10^{-1}$ & $-1.34 \times 10^{-2}$ & 23.5 & 14.2 \\
\hline Picophyto & 0.0 & $92(1.00)$ & $-75(1.00)$ & $6.95 \times 10^{-2}$ & $-6.50 \times 10^{-4}$ & $7.61 \times 10^{-2}$ & 9.4 \\
\hline Nanophyto & 15 & $34(0.76)$ & $-41(0.86)$ & & & & \\
\hline Microphyto & 90 & $16(0.42)$ & $-11(0.28)$ & & & & \\
\hline \multicolumn{8}{|c|}{ Carbon concentrations } \\
\hline Picophyto & 0.0 & $90(1.00)$ & $-79(1.00)$ & $2.63 \times 10^{-3}$ & $-3.06 \times 10^{-5}$ & $7.32 \times 10^{-3}$ & 10.2 \\
\hline Nanophyto & 75 & $-18(0.46)$ & $-8(0.21)$ & & & & \\
\hline Microphyto & 57 & $-5(0.14)$ & $2(0.05)$ & & & & \\
\hline Nanozoo & 0.0 & $91(1.00)$ & $-85(1.00)$ & $1.59 \times 10^{-2}$ & $-3.55 \times 10^{-4}$ & $2.53 \times 10^{-1}$ & 7.2 \\
\hline Microzoo & 49 & $34(0.76)$ & $-70(0.99)$ & & $-2.06 \times 10^{-4}$ & $3.62 \times 10^{-1}$ & 15.0 \\
\hline Mesozoo & 13 & $55(0.96)$ & $-89(1.00)$ & $-2.50 \times 10^{-3}$ & $-8.17 \times 10^{-4}$ & $7.99 \times 10^{-1}$ & 11.8 \\
\hline $\mathrm{Zoo}_{\text {tot }}$ & 1.8 & $72(1.00)$ & $-91(1.00)$ & $1.11 \times 10^{-2}$ & $-1.43 \times 10^{-3}$ & 1.46 & 9.4 \\
\hline Phyto $_{\text {tot }}$ & 30 & $-31(0.72)$ & $-16(0.41)$ & & & & \\
\hline Bacteria & 0.0 & $94(1.00)$ & $-82(1.00)$ & $1.05 \times 10^{-2}$ & $-1.55 \times 10^{-1}$ & $1.21 \times 10^{-1}$ & 6.5 \\
\hline Biomass $_{\text {tot }}$ & 25 & $39(0.83)$ & $-80(1.00)$ & & $-2.34 \times 10^{-4}$ & 4.70 & 13.5 \\
\hline $\mathrm{POC}(\mathrm{L})$ & 94 & $16(0.42)$ & $-68(0.99)$ & & $-1.84 \times 10^{-5}$ & $1.81 \times 10^{-2}$ & 16.6 \\
\hline $\mathrm{POC}(\mathrm{S})$ & 95 & $3(0.08)$ & $-49(0.92)$ & & & & \\
\hline DOC & 0.0 & $95(1.00)$ & $-80(1.00)$ & 1.15 & $-1.39 \times 10^{-2}$ & 11.7 & 5.9 \\
\hline
\end{tabular}

${ }^{a}$ Column 1: $p$ value $p$ associated with the $t$ test between the two groups of seven future and seven present annual values. Columns 2 and 3: correlation factors $C_{S S T}$ and $C_{M L D}$ between those 14 annual value and the 14 hydrodynamical annual NWMS averages (SST and $\left.M L D_{y}\right)$, and associated significant level (SL). Columns 5-7: Coefficients of the linear regression analysis $y=a_{S S T} \times S S T_{y}+a_{M L D} \times M L D_{y}+b$ performed between hydrodynamical and biogeochemical variables for $\mathrm{SL} \geq 0.95$. Column 8: Error $\epsilon_{V_{\text {bio }}}$.

and picophytoplankton chlorophyll biomasses; picoplankton, all zooplankton, bacteria, and total carbon biomasses; DOC and large POC; and GPP, respiration, POC export, and e-ratio.

Second, to estimate the uncertainties linked to the choice of the ORCM, the ARCM, the scenario, and the boundary forcings (rivers and Atlantic hydrographic conditions) in regional climate projections for the Mediterranean region, several physical simulations were performed at CNRM. F. Adloff et al. (Mediterranean Sea response to climate change in an ensemble of 21 st century scenarios, submitted to Climate Dynamics, 2014) uses those simulations to investigate the impact of climate change on the Mediterranean atmospheric and oceanic circulations. In those simulations, the modeling strategy is always the same: the global climate model CNRM-CM (GCM, based on a coupling between a global configuration of ARPEGE-Climate [Déqué et al., 1994] and OPA for the version GCM2 [Madec et al., 1998] or NEMO for the version GCM3 [Madec, 2008]) is used to prescribe the SST information to the ARCM. This ARCM is a configuration of ARPEGEClimate zoomed over the Mediterranean Sea and is used to prescribe the surface forcing to the ORCM. At the Atlantic boundary, 3-D temperature and salinity of the ORCM are relaxed toward climatological values [Reynaud et al., 1998] and anomalies derived from the GCM are added to this climatology between 2000 and 2099. River runoffs come from Vörösmarty et al. [1996] climatological monthly database and the prescribed net Black Sea inflow from Stanev et al. [2000] data set, and anomalies derived from ARCM are added to those runoffs between 2000 and 2099. The first simulation is the one of Somot et al. [2006], used to prescribe river, surface, and lateral boundary conditions to our coupled model (see section 2.2). It used the ORCM OPAMED8 [Madec et al., 1998] and the ARCM3 version, forced by GCM2 under the hypothesis of A2 IPCC [2001] scenario. We call DA9 the 30 year set of the present period 1961-1990 of Somot et al. [2006] simulation and DE9.1 the set of the future period 1970-1999. Exactly the same simulation was then 


\begin{tabular}{|c|c|c|c|c|c|c|}
\hline Simulation & $\begin{array}{l}\text { Oceanic } \\
\text { Model }\end{array}$ & $\begin{array}{l}\text { IPCC [2001] } \\
\text { Scenario }\end{array}$ & $\begin{array}{l}\text { Surface } \\
\text { Fluxes }\end{array}$ & $\begin{array}{c}\text { Rivers and } \\
\text { Black } \\
\text { Sea Anomalies }\end{array}$ & $\begin{array}{c}\text { Atlantic } \\
\text { Anomalies }\end{array}$ & Period \\
\hline PST & Symphonie & & $\mathrm{RCM} 3$ & & & 7 years in 1961-1990 \\
\hline FUT & Symphonie & $\mathrm{A} 2$ & $\mathrm{RCM} 3$ & $\mathrm{RCM} 3$ & $\mathrm{RCM} 3$ & 7 years in $2070-2099$ \\
\hline DA9 & OPAMED8 & & $\mathrm{RCM} 3$ & & & $1961-1990$ \\
\hline DE9.1 & OPAMED8 & $\mathrm{A} 2$ & $\mathrm{RCM} 3$ & $\mathrm{RCM} 3$ & $\mathrm{RCM} 3$ & 2070-2099 \\
\hline HIS & NEMOMED8 & & $\mathrm{RCM} 3$ & & & $1961-1990$ \\
\hline HIS.F & NEMOMED8 & & $\mathrm{RCM} 4$ & & & $1961-1990$ \\
\hline $\mathrm{A} 2$ & NEMOMED8 & $\mathrm{A} 2$ & $\mathrm{RCM} 3$ & $\mathrm{RCM} 3$ & $\mathrm{RCM} 3$ & 2070-2099 \\
\hline $\mathrm{A} 2 . \mathrm{F}$ & NEMOMED8 & $\mathrm{A} 2$ & $\mathrm{RCM} 4$ & $\mathrm{RCM} 3$ & $\mathrm{RCM} 3$ & $2070-2099$ \\
\hline A2.RF & NEMOMED8 & $\mathrm{A} 2$ & $\mathrm{RCM} 4$ & $\mathrm{RCM} 4$ & $\mathrm{RCM} 3$ & 2070-2099 \\
\hline A2.ARF & NEMOMED8 & $\mathrm{A} 2$ & $\mathrm{RCM} 4$ & RCM4 & $\mathrm{RCM} 4$ & 2070-2099 \\
\hline A1B.ARF & NEMOMED8 & $A 1 B$ & RCM4 & RCM4 & RCM4 & 2070-2099 \\
\hline B1.ARF & NEMOMED8 & B1 & $\mathrm{RCM} 4$ & $\mathrm{RCM} 4$ & RCM4 & 2070-2099 \\
\hline
\end{tabular}

performed, but using the ORCM NEMOMED8, a $1 / 8^{\circ}$ configuration of NEMO [Madec, 2008] used to study the Mediterranean circulation [Beuvier et al., 2010; Herrmann et al., 2010]. We call HIS and A2 the present and future 30 year periods of this simulation. GCM3 [Salas y Mélia et al., 2005], the more recent GCM version used for CMIP3 and the IPCC-AR4, was then used to force the ARCM4 version. Keeping the same NEMOMED8 configuration, sensitivity simulations were performed with progressive changes of the surface fluxes (using ARCM4 in HIS.F and A2.F), the river and Black sea runoff anomalies (using ARCM4 in A2.RF), the Atlantic 3-D anomalies (using GCM3 in A2.ARF), and the socioeconomic scenarios (using A1B and B1 in resp. A1B.ARF and B1.ARF). Specifications of each simulation are summarized in Table 4.

Third, for biogeochemical variables and processes significantly related with physical forcing, we applied the linear relationship equation (1) with coefficients of Table 3 to the averages of the annual SST and/or MLD obtained for the 1961-1990 or 2070-2099 periods of the physical simulations detailed above. This produced annual values, reported in Tables 1 and 2, that are estimates of values that would be obtained if we used those simulations to prescribe the physical forcing for Eco3M. To assess the uncertainties related to the different choices of configuration of the modeling strategy, we compare the values obtained for the different simulations.

4.1.1. Choice of the Hydrodynamical Forcing: (PST, FUT)/(DE9.1, DA9)/(HIS, A2)

We first applied the linear relationships to both groups of seven annual SST and MLD values obtained in our NMWS Symphonie simulations (columns PST, FUT of Tables 1 and 2). Averages values obtained for biogeochemical concentrations and processes show differences with modeled values (columns PST $_{m}$, FUT $_{m}$ ) smaller than 1\%, except for POC concentrations ( 4\%) and export ( $6 \%)$.

Comparing values obtained for PST and FUT with those obtained for DA9 and DE9.1 allows to evaluate the difference that would result if we prescribed directly physical forcings from OPAMED8 to Eco3M instead of those of SYMPHONIE. DA9 is warmer $\left(+1.2^{\circ} \mathrm{C}\right)$ and more convective $(168 \mathrm{~m}$ versus $130 \mathrm{~m})$ than PST.

Nutrients concentrations are 1-2\% larger. Differences of chlorophyll and carbon concentration between DA9 and PST are smaller than 5\%. Due to warmer SST and stronger convection, GPP and respiration are respectively 6 and 5\% larger in DA9 and POC export and e-ratio are 9\% and 2\% stronger. SST increase compared to the present period is $1.1^{\circ} \mathrm{C}$ weaker in DE9.1 than in FUT and convection decrease is slightly stronger ( $-107 \mathrm{~m}$ versus $-67 \mathrm{~m}$ ). Trends of nutrients, chlorophyll, and carbon concentrations show the same signs and are very similar in FUT and DE9.1 (1-2\% for nutrients, 0-4\% for chlorophyll, and 1-6\% for carbon, Table 1). GPP and respiration increases are respectively 6 and 5\% weaker in DE9.1 than in FUT, and POC export and e-ratio decreases are respectively $8 \%$ and $2 \%$ stronger.

To investigate the impact of the Mediterranean basin ORCM choice, we compare HIS and A2 (NEMOMED8) with respectively DA9 and DE9.1 (OPAMED8). SST is quasi identical in HIS and DA9, but HIS is much less convective than DA9 (52 m versus $168 \mathrm{~m}$, Table 1). Nutrients availability is consequently weaker in HIS, with concentrations 5-12\% smaller than in DA9, while other biogeochemical groups concentrations are 5-15\% larger. GPP and respiration are respectively $1 \%$ and $3 \%$ larger in HIS, e-ratio is $5 \%$ smaller (Table 2 ) while 
POC export is much weaker (-29\%). OPAMED8 and NEMOMED8 produce long-term trends of same signs for hydrodynamical variables and biogeochemical concentrations. The SST increase is identical $\left(+2.4^{\circ} \mathrm{C}\right)$ in DE9.1 and A2, but the MLD decrease is stronger in DE9.1 ( $-107 \mathrm{~m}$ versus $-22 \mathrm{~m}$ in $\mathrm{A} 2$ ). The nutrient decrease is consequently 2-5 times weaker in A2. Chlorophyll concentrations increase is $4-6 \%$ weaker in A2, and carbon concentrations decrease is $5-11 \%$ weaker. GPP and respiration trends are very similar (difference $\leq 2 \%)$. POC export decrease is $18 \%$ weaker in $\mathrm{A} 2$.

\subsubsection{Choice of the Atmospheric Forcing: (HIS, A2)/(HIS.F, A2.F)}

Due to the difference of atmospheric forcing, in particular to weaker winter heat loss by the ocean (Adloff et al., submitted manuscript, 2014), HIS.F is warmer ( $+0.6^{\circ} \mathrm{C}$, Table 1$)$ and less convective ( $31 \mathrm{~m}$ versus $52 \mathrm{~m}$ ) than HIS in the NWMS. This weaker convection results in smaller nutrients availability (between $-4 \%$ and $-1 \%)$ and POC export (-6\%). Due to the SST increase, the GPP and respiration are very slightly (3\%) larger, as well as the chlorophyll and carbon biomass (between $+1 \%$ and $+5 \%$ ) while the e-ratio is $1 \%$ smaller. The trends of physical forcing between the 20th and 21st have the same signs in A2 and A2.F, with an SST increase and a MLD decrease. However, the SST increase in A2.F compared to HIS.F is larger than in A2 compared to HIS $\left(+3.0^{\circ} \mathrm{C}\right.$ versus $+2.4^{\circ} \mathrm{C}$, Table 1$)$, and the MLD decrease is smaller ( $-4 \mathrm{~m}$ versus $\left.-22 \mathrm{~m}\right)$. The trends between the 20th and 21 st centuries for biogeochemical variables are very similar (differences $\leq 3 \%$ ) and, except for PICOPHYTO $(+3 \%)$, have the same signs. For the GPP, the respiration and the eratio, the differences are negligible $(\leq 2 \%)$. The decrease of POC export is $6 \%$ weaker in A2.F.

\subsubsection{Choice of the Boundary Forcings: River and Atlantic Hydrography: A2.F/A2.RF/A2.ARF} Those three sets of simulations are quasi identical in terms of SST (trend difference $<0.1^{\circ} \mathrm{C}$, Table 1) and MLD (difference $<3 \mathrm{~m}$ ). As a result, the annual values of biogeochemical variables and processes obtained when applying the linear relationships of equation (1) are also identical (the differences between the three sets of simulations is smaller than $1 \%$, Tables 1 and 2).

\subsubsection{Choice of the Scenario: A2.ARF/A1B.ARF/B1.ARF}

Scenarios $A 1 B$ and $B 1$ lead to slightly weaker surface warming than $A 2$ (resp. $+1.7^{\circ} \mathrm{C}$ and $2.5^{\circ} \mathrm{C}$ versus $2.9^{\circ} \mathrm{C}$ ), and the convection trend is almost similar for the three simulations (difference $\leq 4 \mathrm{~m}$ ). The nutrient concentration decrease is very similar (difference $\leq 3 \%$ ). Except for picophytoplankton chlorophyll and carbon biomass, which increases by $7 \%$ more in B1.ARF than in A2.ARF, the trend differences for the other planktonic groups concentrations varies between 0 and 5\%. GPP and respiration increase by $6 \%$ more in B1 than in A2. Differences of change of POC export and e-ratio are negligible $(<1 \%)$.

\subsection{Uncertainties Related to the Biogeochemical Forcing: Initial and Lateral Boundary Conditions} The concentration of biogeochemical groups that are mainly present in the upper layer, i.e., all the groups except allochtonous nutrients (nitrate, phosphate, and silicate), significantly decreases when winter conditions (strong mixing, low temperature) reset them to low values (Figure 3). This suggests that those groups initial and boundary concentrations do not significantly influence the ecosystem functioning during the following cycle. It is the contrary for allochtonous nutrients. To assess the influence of initial and boundary biogeochemical conditions, we therefore performed sensitivity simulations where we kept the same physical forcings as those of the years of the present period (which therefore constitutes the reference for those sensitivity experiments, hereafter called nut $\times 1$ ) and varied the initial and boundary allochtonous nutrient concentrations by factors of 0.5 and 1.5. We ran each simulations in loop until the annual cycle stabilized (see section 2.2): in all the cases, it stabilized after the third cycle. We then compared the fourth annual cycle of the three simulations, nut $\times 1$ and the sensitivity simulations called hereafter nut $\times 0.5$ and nut $\times 1.5$. Annual values of the main biogeochemical variables and processes and absolute and relative differences between nut $\times 0.5$ and nut $\times 1.5$ and nut $\times 1$ are given in Tables 1 and 2 .

For biogeochemical groups other than allochtonous nutrients, concentrations can differ strongly among the three simulations (this is particularly the case for organic matter and mesozooplankton for example, Figure 3), however, this difference is very small in winter due to the winter "reset" effect. This justifies our hypothesis that the groups whose initial and boundary concentration can influence the next annual cycle are those present in deep layers, i.e., the allochtonous nutrients.

The choice of the initial and boundary concentrations has an influence on the concentrations of the different biogeochemical groups that is much stronger than the influence of the physical forcings or the scenario. Except for the picophytoplankton, more adapted to low nutrients concentrations, carbon and chlorophyll 
concentrations are smaller when allochtonous nutrients initial and boundary concentrations are reduced (nut $\times 0.5$ ). The form of the seasonal cycle remains the same for most of the variables or processes in the three simulations, but initial and boundary conditions can strongly affect its amplitude (Figures 3 and 4). Picophytoplankton shows a particular behavior with a pronounced peak in May in nut $\times 0.5$ at the expense of the other phytoplankton groups. The differences of chlorophyll concentrations compared to the reference year vary between 16 and $71 \%$, microphytoplankton being the most sensitive $(-71 /+43 \%)$ and picophytoplankton the less $(-16 /+30 \%)$. Carbon concentration of nanozooplankton $(-17 /+8 \%)$ and bacteria $(-11 /+6 \%)$ are the less sensitive, while those of other groups vary generally between -30 and $+15 \%$, up to $(-65 /+33 \%)$ for microphytoplankton and $-65 /+61 \%$ for large POC. Total biomass varies between -28 and $+15 \%$. GPP and respiration vary between -34 and $+19 \%$. Organic carbon exports vary between -25 and $+10 \%$. Net metabolism $(-7 \% /+3 \%)$ and e-ratio $(-1 /+1 \%)$ are much less variable. For all the biogeochemical variables and processes, the differences induced by the initial and boundary conditions variations are of the order of or larger than the interannual variability ( $\sigma$ in PST $_{m}$, Tables 1 and 2 ) and the average variations obtained between the present and future periods $\left(\Delta_{P S T_{m}}^{F U T_{m}}\right.$ in FUT $\left.{ }_{m}\right)$.

Those results also show that at the scale of the whole domain, the exploitation of nutrients in terms of carbon biomass produced is not optimal: a change in the nutrients availability does not induce a proportional change in the ecosystem components concentration. This is due to physical and biological constraints. First, spatial and temporal variability prevents the food (nutrients, preys, DOM) to be at the same place at the same time as the consumers. Second, biological constraints limit the biomass growth: nature does not allow for infinite growth. This limitation is contained in the mathematical formulation of the biogeochemical processes in our model.

\section{Summary and Conclusions}

This study represents one of the first attempts to model and assess the effects of oceanic and atmospheric long-term evolution on the NWMS pelagic planktonic ecosystem in terms of functioning, seasonal evolution, and carbon cycle. For that, we developed a 3-D coupled physical-biogeochemical model and performed and compared two groups of 7 simulations under present (20th century) and future (end of 21st century) climate conditions.

Our results suggest that at the end of the 21 st century, the seasonal evolution and interannual variability of the ecosystem components and biogeochemical processes would be very similar at a first order to those observed for the end of the 20th century. Quantitative differences are however obtained at a second order, mainly resulting from the weakening of winter convection and the warming of the surface layer between the present and future periods. Figure 5 shows a synthesis of our results. First the spring bloom occurs 1 month earlier. Second, the convection weakening induces a significant decrease of nutrients availability $(-12 \%$ for nitrate), while the water warming induces a GPP increase (+19\%). The DOC phytoplanktonic exudation consequently increases $(+33 \%)$, which favors the bacteria growth (+24\%). The planktonic community structure evolves toward larger biomasses of small-size groups (picophytoplankton $(+25 \%)$, bacteria $(+18 \%)$ and nanozooplankton $(+17 \%)$ ), which are the only groups that show statistically significant changes. The combination between the surface warming and the nutrient depletion therefore results in a strengthening of the microbial loop activity. These alterations of environmental conditions favor the development of lower size classes of plankton and it strengthens their competition for nutrient resource (nitrogen and more particularly phosphorus). The increase in the abundance of these organisms favors the development of their potential predator, i.e., nanozooplankton. Mostly due to the bacteria respiration increase, the total respiration increases $(+20 \%)$. The predicted evolution of the planktonic ecosystem does not modify the status of the NWMS regarding crucial processes of the carbon cycle which do not vary significantly, such as the net metabolism of inorganic carbon, that remains positive, and the deep export of organic carbon. From the point of view of the carbon fixation and export relative to nutrients availability, we can consider that the ecosystem becomes more efficient since it is able to store the same quantity of carbon using less nutrients. This conclusion is supported by the results showing that planktonic groups use less nutrients to fix the same amount of carbon: evolution of DOM (DOM phytoplanktonic exudation and increase of DOC:DON and DOC:DOP ratios, section 3.2.3), of bacteria excretion (increase in the ratios of bacteria DIM excretion versus DOM absorption, section 3.2.4), and of the stoechiometry of the phytoplankton, whose internal N:C and P:C quotas slightly increase (not shown). To deal with the decrease of nutrients availability, the phytoplankton uses the fact that it can adapt its composition to 


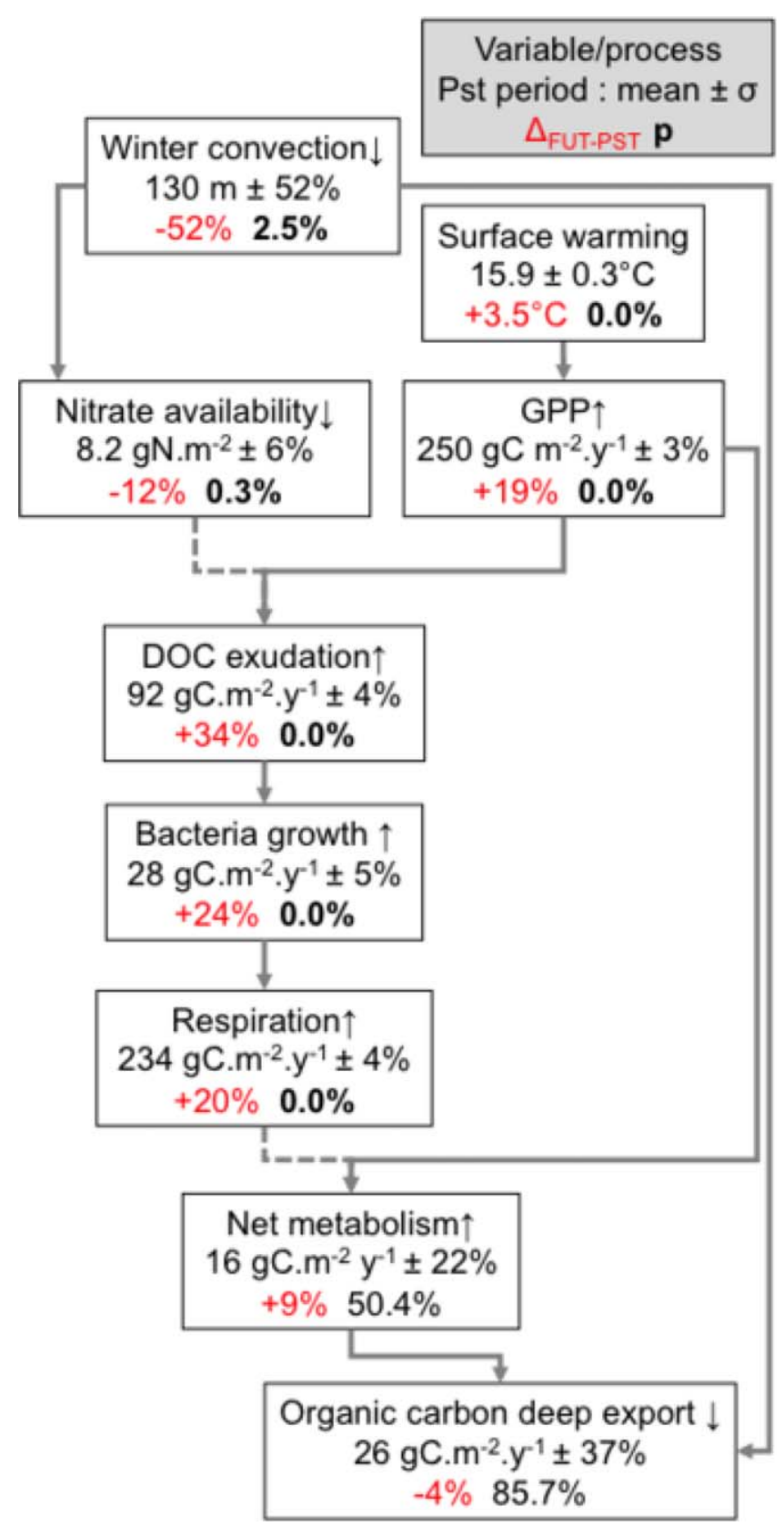

Figure 5. Synthesis scheme showing the effect of the interannual variability and long-term evolution of oceanic conditions on the NWMS pelagic planktonic ecosystem and associated carbon cycle. For each component or process, we indicate the mean average value and its relative variability under present conditions in black, its relative long-term evolution in red and the $\mathrm{p}$ value in black, bold when $\leq 5 \%$. Plain, resp. dashed lines, show a positive, resp. negative relationship. fix the same amount of carbon with less nutrients. This also means that those quotas are further in the future from the maximal quotas, i.e., the optimal trophic conditions quotas (that they never not reach, even in the present period). This increase of the ecosystem efficiency is therefore based on the adaptability of the phytoplankton composition associated with an intensification of the microbial loop and a more intense regenerated production.

To increase the robustness of those results, we explored the uncertainties associated with the choice of the biogeochemical forcing, the physical forcing and the scenario hypothesis on the modeling of the planktonic pelagic ecosystem and associated carbon cycle. Lateral physical boundaries tested here (river runoffs and Atlantic hydrography west of the Gibraltar strait) do not influence significantly the projections of the surface temperature and winter convection, hence of the biogeochemical components and processes. The choice of the atmospheric forcing has a larger influence on the winter convection intensity, but its influence on the biogeochemical projections stays weak, with differences generally smaller than $5 \%$. Differences of projections associated with the choice of the socioeconomic scenario remain smaller than $7 \%$. The choice of the hydrodynamical model has a stronger impact and can induce large differences of physical forcing. They induce differences of biogeochemical carbon and chlorophyll concentrations varying between 4 and $15 \%$. GPP and respiration show very small differences, while POC export

differences can reach $30 \%$. Those differences are mainly induced by the differences of MLD associated with the modeling configuration while the SST differences have weaker impact. Differences of biogeochemical projections however stay smaller than $10 \%$. Note that other physical modeling studies [Thorpe and Bigg, 2000; Bozec, 2006] also predicted a sea warming and a weakening of the convection in the NWMS by the end of the 21 st century, our results concerning the impact of the physical forcing suggest that the response of the biogeochemical model to these physical projections would be similar to that predicted here. Finally, trends of biogeochemical variables and processes have the same signs in all the simulations examined here to assess the uncertainties associated with the physical forcing. 
Sensitivity simulations performed to test the influence of the biogeochemical initial and boundary conditions show that this influence is strong and is mainly associated with the initial and boundary conditions of allochtonous nutrients concentrations. The ranges or variations of biogeochemical concentrations and processes associated with the modifications of these conditions are of the order of or one order larger than their modeled ranges of interannual variability and long-term trends. Moreover, the general form of the seasonal cycle remains unchanged for most of the components and processes. However, boundary conditions can modify it for picophytoplankton, favoring spring peaks for strongly depleted conditions. This shows that it is essential to improve the realism of the biogeochemical boundary conditions and take into account their evolution. This requires to develop large-scale coupled simulations over the 20th and 21 st centuries but also to assess and account for the variability and long-term evolution of the atmospheric, terrestrial, and bottom fluxes of matters.

Another of uncertainties is associated with the design of the biogeochemical model itself. A strong effort was made to adapt the model to the NWMS ecosystem conditions. However, the representation of biogeochemical processes in our model does not enable to represent all the changes that could occur in the ecosystem under the influence of climate change: species adaptation to warming, new species apparition, and shift to another trophic regime. It would be necessary to better take into account the evolution and influence of the parameters that are likely to evolve the most by the end of the 21 st century, in particular water temperature and inorganic carbon concentration. The control by the temperature of the autotroph and heterotroph plankton growth is represented through a function of Eppley type [Eppley, 1972] in our model. This exponential parameterization of temperature influence does not allow to represent the potential decline, respectively development, of some species presently close to, respectively far from, their temperature optimum. There is no explicit state variable for inorganic carbon concentrations in our model. The effects of inorganic carbon variations due to physical processes on the planktonic ecosystem, for example, on the photosynthesis rate [Burkhardt et al., 2001] or phytoplankton stoechiometry [Feely et al., 2004; Fu et al., 2007], are consequently not taken into account. Moreover, the mechanisms of dissolution of atmospheric $\mathrm{CO}_{2}$ and the evolution of dissolved inorganic carbon due to chemical equilibrium are not represented here. For that it will be necessary to include a module of alkalinity dynamics and specific inorganic carbon absorption as done by Raick-Blum [2005]. This would allow to assess the status and intensity of the carbon pump due to physical and chemical processes in the NWMS. More generally, groups involved in the development and use of hydrodynamical and biogeochemical models should work with the constant objective to improve the realism of those models by making profit of the available observations: continuously growing data set of observed changes in the ocean provide information that should enable to introduce, for example, biota plasticity at physiological and community level. Finally, testing thoroughly the influence of the choice of the configuration of the models (biogeochemical/hydrodynamical/atmospheric at the NWMS/Mediterranean/global scales) requires a strong coordinate work involving several research groups that run different models. Part of this work belongs to the objectives of ongoing projects (e.g., AMICO-Bio which contains, among other, the comparison of four different coupled models and the assessment of the influence of biogeochemical lateral forcing).

Acknowledgments

This work was partly funded by the SESAME project (Contract No. GOCE2006-036949) from the sixth Framework Program of the European Commission. It is a contribution to the HyMeX (HYdrological cycle in Mediterranean EXperiment) and MerMEx (Marine Ecosystems Response in the Mediterranean Experiment) projects from the MISTRALS program. We thank CNRM for providing the regional ocean-atmosphere simulations that were used to force our coupled model. We warmly thank Aurelien Ribes for his advices about the statistical diagnostics. Numerical results used to produce the results of this paper are available by contacting the authors at marine.herrmann@ird.fr.

\section{References}

Auclair, F., C. Estournel, P. Marsaleix, and I. Pairaud (2006), On coastal ocean embedded modeling, Geophys. Res. Lett., 33, L14602, doi: 10.1029/2006GL026099.

Auger, P., F. Diaz, C. Ulses, C. Estournel, J. Neveux, F. Joux, M. Pujo-Pay, and J. Naudin (2011), Functioning of the planktonic ecosystem of the Rhone river plume (NW Mediterranean) during spring and its impact on the carbon export: A field data and 3-D modelling combined approach, Biogeosciences, 8, 3231-3261, doi:10.5194/bg-8-3231-2011.

Béthoux, J.-P., B. Gentili, and D. Tailliez (1998), Warming and freshwater budget change in the Mediterranean since the 1940s, their possible relation to greenhouse effect, Geophys. Res. Lett., 25(7), 1023-1026.

Béthoux, J.-P., P. Morin, and D. Ruiz-Pino (2002), Temporal tends in nutrient ratios: Chemical evidence of Mediterranean ecosystem changes driven by human activity, Deep Sea Res., Part II, 49, 2007-2016.

Beuvier, J., F. Sevault, M. Herrmann, K. Kontoyiannis, W. Ludwig, M. Rixen, E. Stanev, K. Béranger, and S. Somot (2010), Modelling the Mediterranean Sea interannual variability over the last 40 years: Focus on the Eastern Mediterranean Transient (EMT), J. Geophys. Res., 115, C08017, doi:10.1029/2009JC005950.

Bopp, L., P. Monfray, O. Aumont, J.-L. Dufresne, H. L. Treut, G. Madec, L. Terray, and J. Orr (2001), Potential impact of climate change on marine export production, Global Biogeochem. Cycles, 15(1), 81-99.

Bopp, L., O. Aumont, P. Cadule, S. Alvain, and M. Gehlen (2005), Response of diatoms distribution to global warming and potential implication: A global modeling study., Geophys. Res. Lett., 32, L19606, doi:10.1029/2005GL023653.

Bosc, E., A. Bricaud, and D. Antoine (2004), Seasonal and interannual variability in algal biomass and primary production in the Mediterranean Sea, as derived from 4 years of SeaWifs observations, Global Biogeochem. Cycles, 18, GB1005, doi:10.1029/2003GB002034.

Bozec, A. (2006), La circulation thermohaline de la Mer Méditerranée sous des climats présent et futur, PhD thesis, Univ. Paris 6, Paris. 
Burkhardt, S., F. Amoroso, U. Riebesell, and D. Sultmeyer (2001), $\mathrm{CO}_{2}$ and $\mathrm{HCO}_{3}$ uptake in marine diatoms acclimated to different $\mathrm{CO}_{2}$ concentrations, Limnol. Oceanogr., 46(6), 1378-1391.

Cermeno, P., S. Dutkiewicz, R. Harris, M. Follows, O. Schofield, and P. Falkowski (2008), The role of nutricline depth in regulating the ocean carbon cycle, Proc. Natl. Acad. Sci. U. S. A., 105(51), 20,344-20,349.

Christensen, J., T. Carter, and F. Giorgi (2002), PRUDENCE employs new methods to assess European climate change, EOs Trans. AGU, 83 , 147.

Chust, G., et al. (2014), Biomass changes and trophic amplification of plankton in a warmer ocean, Global Change Biol., 20, 2124-2139, doi: $10.1111 / \mathrm{gcb} .12562$

Cullen, J. (1990), On models of growth and photosynthesis in phytoplankton, Deep Sea Res., Part A, 37(4), 667-683.

Déqué, M., C. Dreveton, A. Braun, and D. Cariolle (1994), The ARPEGE-IFS atmosphere model: A contribution to the French community climate modelling, Clim. Dyn., 10, 249-266.

Eisenhauer, L., F. Carlotti, M. Baklouti, and F. Diaz (2009), Zooplankton population model coupled to a biogeochemical model of the North Western Mediterranean Sea ecosystem, Ecol. Modell., 220, 2865-2876.

Eppley, R. (1972), Temperature and phytoplankton growth in sea, Fish. Bull., 70, 1063-1085.

Feely, R., C. Sabine, K. Lee, W. Berelson, J. Kleypas, V. Fabry, and F. Millero (2004), Impact of anthropogenic $\mathrm{CO}_{2}$ on the $\mathrm{CaCO}_{3}$ system in the oceans, Science, 305(5682), 362-366, doi:10.1126/science.1097329.

Frolicher, T., F. Joos, G. Plattner, M. Steinacher, and S. Doney (2009), Natural variability and anthropogenic trends in oceanic oxygen in a coupled carbon cycle-climate model ensemble, Global Biogeochem. Cycles, 23, 1-15, doi:10.1029/2008GB003316.

Fu, F., M. Warner, Y. Zhang, Y. Feng, and D. Hutchins (2007), Effects of increased temperature and $\mathrm{CO}_{2}$ on photosynthesis, growth, and elemental ratios in marine Synechococcus and Prochlorococcus (Cyanobacteria), J. Phycol., 43(3), 485-496.

Garcia-Comas, C., L. Stemmann, F. Ibanez, L. Berline, M. Mazzocchi, S. Gasparini, M. Picheral, and G. Gorsky (2011), Zooplankton long-term changes in the NW Mediterranean Sea: Decadal periodicity forced by winter hydrographic conditions related to large-scale atmospheric changes?, J. Mar. Syst., 87, 216-226.

Giorgi, F. (2006), Climate change hot-spots, Geophys. Res. Lett., 33, L08707, doi:10.1029/2006GL025734.

Herrmann, M. (2007), Formation et devenir des masses d'eau en Méditerranée Nord-Occidentale. Influence sur l'écosysteme plantonique pélagique. Variabilité interannuelle et changement climatique, PhD thesis, Univ. de Toulouse, University of Toulouse, Toulouse, France.

Herrmann, M., and S. Somot (2008), Relevance of ERA40 dynamical downscaling for modeling deep convection in the Mediterranean Sea, Geophys. Res. Lett., 35, L04607, doi:10.1029/2007GL032442.

Herrmann, M., C. Estournel, M. Déqué, P. Marsaleix, F. Sevault, and S. Somot (2008a), Dense water formation in the Gulf of Lions shelf: Impact of atmospheric interannual variability and climate change, Cont. Shelf Res., 28(15), 2092-2112, doi:10.1016/j.csr.2008.03.003.

Herrmann, M., S. Somot, F. Sevault, C. Estournel, and M. Déqué (2008b), Modeling the deep convection in the Northwestern Mediterranean sea using an eddy-permitting and an eddy-resolving model: Case study of winter 1986-1987, J. Geophys. Res., 113, C04011, doi:10.1029/ 2006JC003991.

Herrmann, M., F. Sevault, J. Beuvier, and S. Somot (2010), What induced the exceptional 2005 convection event in the northwestern Mediterranean basin ? Answers from a modeling study, J. Geophys. Res., 115, C08029, doi:10.1029/2009JC005749.

Herrmann, M., F. Diaz, C. Estournel, P. Marsaleix, and C. Ulses (2013), Impact of atmospheric and oceanic interannual variability on the Northwestern Mediterranean Sea pelagic planktonic ecosystem and associated carbon cycle, J. Geophys. Res. Oceans, 118, 5792-5813, doi:10.1002/jgrc.20405.

IPCC (2001), Climate Change 2001. The Scientific Basis. Contribution of Working Group I to the Third Assessment Report of the IPCC, edited by J. T. Houghton et al., 881 pp., Cambridge Univ. Press, Cambridge, U. K.

IPCC (2013), Climate Change 2013: The Physical Science Basis. Contribution of Working Group I to the Fifth Assessment Report of the Intergovernmental Panel on Climate Change, edited by T. F. Stocker et al., Cambridge Univ. Press, Cambridge, U. K.

Joos, F., G.-K. Plattner, T. Stocker, O. Marchal, and A. Schmittner (1999), Global warming and marine carbon cycle feedbacks on future atmospheric $\mathrm{CO}_{2}$, Science, 284, 464-467.

Kouwenberg, J. (1998), Shift in copepod populations and long-term changes in the Northwestern Mediterreanean. An overview, final report of SCOR/IOC working group 93 'Pelagic Biogeography,' Intergov. Oceanogr. Comm., Paris.

Lazzari, P., C. Solidoro, V. Ibello, S. Salon, A. Teruzzi, K. Béranger, S. Colella, and A. Crise. (2011), Seasonal and inter-annual variability of plankton chlorophyll and primary production in the Mediterranean Sea: A modelling approach, Biogeosciences, 9, $217-233$.

Lazzari, P., G. Mattia, C. Solidoro, S. Salon, A. Crise, M. Zavatarelli, P. Oddo, and M. Vichi (2013), The impacts of climate change and environmental management policies on the trophic regimes in the Mediterranean Sea: Scenario analyses, J. Mar. Syst., 135, 137-149, doi: 10.1016/j.jmarsys.2013.06.005.

Lévy, M., P. Klein, and A.-M. Treguier (2001), Impact of sub-mesoscale physics on production and subduction of phytoplankton in an oligotrophic regime, J. Mar. Res., 59, 535-565.

Madec, G. (2008), NEMO ocean engine, Tech. Rep. 27 ISSN No 1288-1619, Pole de modélisation, Inst. Pierre-Simon Laplace, Paris.

Madec, G., P. Delecluse, M. Imbard, and C. Levy (1998), Opa 8.1, ocean general circulation model, reference manual, Tech. Rep. 11, Pôle de modélisation, IPSL/LODYC, Paris.

Maier-Reimer, E., U. Mikolajewicz, and A. Winguth (1996), Future ocean uptake of $\mathrm{CO}_{2}$ : Interaction between ocean circulation and biology, Clim. Dyn., 12, 711.

Marinov, I., S. Doney, and I. Lima (2010), Response of ocean phytoplankton community structure to climate change over the 21 st century: Partitioning the effects of nutrients, temperature and light, Biogeosciences, 7, 3941-3959.

Marsaleix, P., F. Auclair, and C. Estournel (2009), Low-order pressure gradient schemes in sigma coordinate models: The seamount test revisited, Ocean Modell., 30, 169-177, doi:10.1016/j.ocemod.2009.06.011.

Marty, J.-C., and J. Chiaverini (2010), Hydrological changes in the Ligurian Sea (NW Mediterranean, DYFAMED site) during 1995-2007 and biogeochemical consequences, Biogeosciences, 7, 2117-2128, doi:10.5194/bg-7-2117-2010.

Marty, J.-C., J. Chiaverini, M.-D. Pizay, and B. Avril (2002), Seasonal and interannual dynamics of nutrients and phytoplankton pigments in the western Mediterranean Sea at the DYFAMED time-series station (1991-1999), Deep Sea Res., Part II, 49, 1965-1985.

MerMEx Group: X. Durrieu de Madron, et al. (2011), Marine ecosystems' responses to climatic and anthropogenic forcings in the Mediterranean, Prog. Oceanogr., 91, 97-166, doi:10.1016/j.pocean.2011.02.003.

Mertens, C., and F. Schott (1998), Interannual variability of deep-water formation in the Northwestern Mediterranean, J. Phys. Oceanogr., $28,1410-1424$

Molinero, J., F. Ibanez, P. Nival, E. Buecher, and S. Souissi (2005), The North Atlantic climate and the northwestern Mediterranean plankton variability, Limnol. Oceanogr., 50(4), 1213-1220. 
Molinero, J., F. Ibanez, S. Souissi, E. Buecher, S. Dallot, and P. Nival (2008), Climate control on the long-term anomalous changes of zooplankton communities in the northwestern Mediterranean, Global Change Biol., 14, 11-26.

Moran, X., A. Lopez-Urrutia, A. Calvo-Diaz, and W. Li (2010), Increasing importance of small phytoplankton in a warmer ocean, Global Change Biol., 16, 1137-1144.

Morel, A., and J. M. André (1991), Pigment distribution and primary production in the Western Mediterranean as derived and modeled from coastal zone color scanner observations, J. Geophys. Res., 96(C7), 12,685-12,698.

Raick-Blum, C. (2005), Mathematical modelling of the Ligurian Sea ecosystem using models of different complexities. Application of a Kalman filter to improve models reliability, PhD thesis, Univ. de Liège, University of Liège, Liège, Belgium.

Reynaud, T., P. Legrand, H. Mercier, and B. Barnier (1998), A new analysis of hydrographic data in the Atlantic and its application to an inverse modeling study, Int. WOCE Newslett., 32, 29-31.

Salas y Mélia, D., F. Chauvin, M. Déqué, H. Douville, J. Guérémy, P. Marquet, S. Planton, J. Royer, and S. Tyteca (2005), Description and validation of CNRM-CM3 global coupled climate model, Tech. Rep. 103, Groupe de Météorol. de Grande Echelle et Climat, CNRM, Toulouse, France.

Sarmiento, J., et al. (2004), Response of ocean ecosystems to climate warming, Global Biogeochem. Cycles, 18, GB3003, doi:10.1029/ 2003 GB002134.

Sarmiento, J. L., T. M. C. Hughes, R. J. Stouffer, and S. Manabe (1998), Simulated response of the ocean carbon cycle to anthropogenic climate warming, Nature, 393(6682), 245-249.

Schmittner, A., A. Oschlies, H. Matthews, and E. Galbraith (2008), Future changes in climate, ocean circulation, ecosystems, and biogeochemical cycling simulated for a business-as-usual $\mathrm{CO}_{2}$ emission scenario until year $4000 \mathrm{AD}$, Global Geochem. Cycles, 22, GB1013, doi: $10.1029 / 2007$ GB002953.

Somot, S., F. Sevault, and M. Déqué (2006), Transient climate change scenario simulation of the Mediterranean Sea for the 21st century using a high resolution ocean circulation model, Clim. Dyn., 27, 851-879, doi:10.1007/s00382-006-0167-z.

Stanev, E., P.-Y. Le Traon, and E. Peneva (2000), Sea level variations and their dependency on meteorological and hydrological forcing: Analysis of altimeter and surface data for the Black Sea, J. Geophys. Res., 105(C7), 17,203-17,216.

Steinacher, M., et al. (2010), Projected 21st century decrease in marine productivity: A multi-model analysis, Biogeosciences, 7, $979-1005$.

Thorpe, R., and G. Bigg (2000), Modelling the sensitivity of the Mediterranean outflow to anthropogenically forced climate change, Clim. Dyn., 16, 355-368.

Turley, C. M. (1999), The changing Mediterranean Sea—A sensitive ecosystem?, Prog. Oceanogr., 44, 387-400.

Vasquez-Dominguez, E., D. Vaqué, and J. Gasol (2007), Ocean warming enhances respiration and carbon demand of coastal microbial plankton, Global Change Biol., 13(7), 1327-1334.

Vörösmarty, C., B. Fekete, and B. Tucker (1996), Global River Discharge Database, RivDis, International Hydrological Program, Global Hydrological Archive and Analysis Systems, UNESCO, Paris. 